\title{
Assessment of the spatio-temporal variability of the added value on precipitation of convection- permitting simulation over the Iberian Peninsula using the RegIPSL regional earth system model
}

Namendra Kumar Shahi ( $\nabla$ namendra-kumar.shahi@Imd.polytechnique.fr )

LMD: Laboratoire de Meteorologie Dynamique https://orcid.org/0000-0002-7431-3689

Jan Polcher

LMD: Laboratoire de Meteorologie Dynamique

Sophie Bastin

LATMOS: Laboratoire Atmospheres Milieux Observations Spatiales

Romain Pennel

LMD: Laboratoire de Meteorologie Dynamique

Lluís Fita

CIMA: Centro de Investigaciones del Mar y la Atmosfera

\section{Research Article}

Keywords: Added value, Dynamical downscaling, RegIPSL model, Convection-permitting simulation, Precipitation events

Posted Date: April 28th, 2021

DOI: https://doi.org/10.21203/rs.3.rs-469400/v1

License: (c) (i) This work is licensed under a Creative Commons Attribution 4.0 International License. Read Full License

Version of Record: A version of this preprint was published at Climate Dynamics on January 17th, 2022. See the published version at https://doi.org/10.1007/s00382-022-06138-y. 

simulation over the Iberian Peninsula using the RegIPSL regional earth system model

1. CNRS-IPSL Laboratoire de Météorologie Dynamique (LMD), École Polytechnique, Palaiseau, France.

2. LATMOS/IPSL, UVSQ Université Paris-Saclay, Sorbonne Universite, CNRS, Guyancourt, France.

3. Centro de Investigaciones del Mar y la Atmósfera (CIMA), CONICET-UBA, CNRS-IRD-CONICET-UBA IRL3351 IFAECI, C. A. Buenos Aires, Argentina.

$25 *$ Corresponding author

26 Dr. Namendra Kumar Shahi

27 CNRS/IPSL Laboratoire de Météorologie Dynamique (LMD)

28 École Polytechnique, Palaiseau-91128, France

29 E-mail: nkshahi2010@gmail.com, namendra-kumar.shahi@lmd.polytechnique.fr 
In this study, we have assessed the added value on the spatio-temporal distribution of the precipitation of 7 58 convection-permitting simulation (3km) compared to the parent coarser-scale parameterized convection simulation (20km) with the high-resolution observational datasets i.e. SPREAD (5km) and IBERIA01 (10km) over the Iberian Peninsula in all four seasons during 2000-2009. Both simulations are evaluation runs based on ERA-Interim reanalysis and performed with the RegIPSL regional earth system model in the frame of the European Climate Prediction system (EUCP) H2020 project and COordinated Regional climate Downscaling Experiment (CORDEX). We have not found significant improvement in the convection-permitting simulation compared to the parent coarser-scale simulation for the seasonal mean precipitation of the Iberian Peninsula except the spatial variation over mountainous peaks. The kilometer-scale simulation significantly underestimates the observed seasonal mean precipitation over the western parts of the Iberian Peninsula compared to the coarser-scale simulation, which may be attributed to a change of local dynamics in the kilometer-scale simulation with a weakening and southward shifts of the westerly winds and also an enhancement of warm and dry southerly winds over the Iberian Peninsula. However, the added value of kilometer-scale simulation over the driving coarser-scale simulation is obtained for various indices; in the representation of the spatio-temporal distribution of the wet-day precipitation frequency and intensity, and the extreme/heavy precipitation events for each season at both resolutions i.e. downscaled and upscaled. It has also been noted that the spatio-temporal distribution of precipitation for all metrics used varies between the two observational datasets for all seasons.

Keywords: Added value, Dynamical downscaling, RegIPSL model, Convection-permitting simulation, Precipitation events (1) 51 2 3 54 5 


\section{Introduction}

Regional climate models (RCMs) have proven to be a powerful/useful tool for dynamically downscaling the coarse-scale information/datasets at the regional-to-local scale (Prein et al. 2015). The coarse-scale information is handed over to an RCM via the lateral boundaries, and the information is usually provided from either general circulation models (GCMs), reanalysis, or large-scale regional models. In the last two-three decades, the RCMs have been used for improving our understanding of regional climate processes of different parts of the world, and also used for impact assessment studies. Also, considerable efforts have been/are being made to further advance and improve the RCMs by increasing their complexity and resolution. Recent advances in supercomputer computing power/resources have allowed limited-area RCMs to be run at kilometer-scale grid spacing (also known as convection-permitting/resolving/allowing). Increasing the spatial resolution towards convection-permitting scales ( $<=4 \mathrm{~km}$; Weisman et al. 1997) can resolve deep convection explicitly on the model grid without the need for a convective parametrization scheme (Hohenegger et al. 2008; Kendon et al. 2012; Prein et al. 2015; Kendon et al. 2017). As several studies have shown that the parameterizations of sub-grid scale convection are a key source of errors and uncertainties in the climate model simulations (Bechtold et al. 2004; Randall et al. 2007; Déqué et al. 2007; Hohenegger et al. 2008; Brockhaus et al. 2008). Also, increasing resolution leads to a better representation of orography and land surface fields which are crucial for the initiation of convection in complex terrain (Hohenegger et al. 2008), and also provides a step-change in our capability for understanding future climate change at local to regional scale and for and high-impact extreme weather events that greatest impact society (Rasmussen et al. 2020; Helsen et al. 2020; Kendon et al. 2019, 2021).

Over the last decade, several studies have demonstrated the clear benefits and added value of the convectionpermitting models in the simulation of precipitation characteristics with much greater realism, including the diurnal cycles, spatial distribution of precipitation, intensity and frequency distribution, and extremes compared to the coarse-scale model (Prein et al. 2015; Meredith et al. 2015; Fosser et al. 2015; Lind et al. 2016; Brisson et al. 2016; Liu et al. 2017; Leutwyler et al. 2017; Zittis et al. 2017; Karki et al. 2017; Berthou et al. 2018; Fumière et al. 2019; Broucke et al. 2019; Li et al. 2019; Chang et al. 2020; Lind et al. 2020; Knist et al. 2020; Kouadio et al. 2020; Coppola et al. 2020; Zhou et al. 2021; Li et al. 2021; Ban et al. 2021).

Some recent coordinated efforts towards a better understanding of the regional climate modelling at kilometer resolutions are undergoing like; the dedicated Coordinated Regional Downscaling Experiment Flagship Pilot Studies (CORDEX-FPS; https://cordex.org/experiment-guidelines/flagship-pilot-studies/) on Convective phenomena at highresolution over Europe and the Mediterranean and also within the European Climate Prediction System (EUCP; 
https://www.eucp-project.eu/). Within these projects, several regional modelling groups across Europe are conducting climate simulations in a common greater Alpine domain with horizontal resolutions around $3 \mathrm{~km}$, with the aim to generate/build multi-model ensembles of simulations at the convective-permitting scales over a decade-long period to explore the capabilities and uncertainties of the convective-permitting model simulations in a systematic manner for present and future climates (Coppola et al 2020; Ban et al. 2021). The ensemble of ERA-Interim driven present-day convectionpermitting climate simulations have shown superior performance in simulating the precipitation characteristics compared to coarse-resolution climate simulations, although differences between the kilometer-scale simulations and observations still exist (Coppola et al 2020; Ban et al. 2021). Panosetti et al. (2019) have shown that the kilometer-scale simulations are climatologically more robust in case of strong orographic forcing (domain over the European Alps) and less robust in central German.

Keeping in mind the usage and added value of convection-permitting model simulations in the above literature, here we evaluate the added value of the convection-permitting/resolving simulation ( $3 \mathrm{~km}$ resolution) compared to the coarser-resolution parameterized convection simulation $(20 \mathrm{~km}$ resolution) in the representation of the spatio-temporal pattern of the observed mean and extreme precipitation over the Iberian Peninsula for all four seasons [i.e. DecemberJanuary-February (DJF; Winter), March-April-May (MAM; Spring), June-July-August (JJA; Summer), and SeptemberOctober-November (SON; Autumn)] for the period of 2000-2009. Both simulations are based on the ERA-Interim reanalysis (Dee et al. 2011) and have been performed using a recently developed regional climate model called RegIPSL by the Institut Pierre Simon Laplace (IPSL, https://gitlab.in2p3.fr/ipsl/lmd/intro/regipsl/regipsl/-/wikis/home) group in the frame of the European Climate Prediction system (EUCP) H2020 project and COordinated Regional climate Downscaling Experiment (CORDEX), and details about this model and simulations are given in the next section. The simulated precipitation is evaluated with the available high-resolution observational gridded datasets i.e. SPREAD (5 km) and IBERIA01 $(10 \mathrm{~km})$. In the comparison of the model-simulated results with observations, the uncertainty associated with the observational datasets especially over mountainous regions due to the sparseness of rain gauge stations at high elevations must be taken into account (Sevruk 1985; Frei et al. 2003). Recent studies actually report that total annual precipitation can be better represented by well-configured high-resolution atmospheric models in mountainous terrain, than with spatial estimates derived from observational products (Lundquist et al. 2020).

The research paper is mainly structured into three sections. In section 2, we have presented a detailed description of the model configuration for the two simulations, as well as observational datasets used for validation and methodology used. 
116 A detailed analysis of the added value of the fine-scale simulation over the driving coarse-scale simulation against the

117 observations is presented in section 3, and finally, the summary and conclusions are given in section 4 .

\section{Model simulations, Data, and Methodology}

\section{$119 \quad 2.1$ Model simulations and data}

In the frame of the EUCP H2020 project and CORDEX, we have performed the ERA-Interim driven regional

climate simulations with the coupled atmosphere-land RegIPSL model over the European domain at $20 \mathrm{~km}$ horizontal resolution (EUR20; with parameterized convection) and also over the European South-West domain at 3 km (SWE3; convection-permitting/resolving) horizontal grid spacing for the period of 1999-2009 (the first year period has been used as a model spin-up). The European South-West domain (i.e. Iberian Peninsula) is an area with a rich diversity of climates that is affected by several high-impact extreme events such as droughts and flash floods, for which the coupling processes between the land surface and the atmosphere play an important/key role. The experiment is performed as a chain of simulations while the EUR20 simulation is forced by the 6-hourly ERA-Interim initial and lateral boundary conditions (ICLBCs) and the SWE3 simulation is forced by the 3-hourly EUR20 simulated IC-LBCs. The model domain with terrain height in the meters for the EUR20 and SWE3 simulations is shown in Figs. 1a and 1b, respectively.

The RegIPSL is a newly developed regional earth system model and is maintained at the Institut Pierre Simon Laplace (IPSL). The atmospheric component of the RegIPSL model is WRF (Weather Research and Forecasting; Skamarock et al. 2008; Fita et al. 2019) model, which is coupled to the ORCHIDEE (Organising Carbon and Hydrology In Dynamic Ecosystems; Krinner et al. 2005) land-surface model and NEMO (Nucleus for European Modelling of the Ocean; Madec et al. 1998) ocean model. We have used the OASIS coupler (https://portal.enes.org/oasis) for coupling, and XIOS (or XML I/O Server, http://forge.ipsl.jussieu.fr/ioserver) libraries are used for the management of the input/output. The details of the model configuration and the WRF physical schemes are given in Table 1.

The high-resolution SPREAD $\left(0.05^{\circ} \times 0.05^{\circ}\right.$; Serrano Notivoli et al. 2017) and IBERIA01 $\left(0.1^{\circ} \times 0.1^{\circ}\right.$; Herrera et al. 2019) daily gridded mean precipitation observational datasets have been used as reference datasets for the validation of the model simulated precipitation. The SPREAD dataset is based on the 12858 observatories and is available at land points of Spain, while the IBERIA0 is based on a total of 3761 rain gauge stations and covers the landmass of Spain as well as Portugal. A detailed description of these datasets can be found from the references given above. 
Table 1. Description of model configurations.

\begin{tabular}{|c|c|c|}
\hline \multirow[t]{2}{*}{ Description } & \multicolumn{2}{|c|}{ Selection } \\
\hline & EUR20 simulation & SWE3 simulation \\
\hline WRF version & 3.7 .1 & 3.7.1 \\
\hline Dynamic solver & ARW & ARW \\
\hline Horizontal grid spacing & $20 \mathrm{~km}$ & $3 \mathrm{~km}$ \\
\hline Grid dimensions & $301 \times 193$ & $581 \times 651$ \\
\hline Vertical levels & 46 (top $50 \mathrm{hPa}$ ) & 46 (top $70 \mathrm{hPa}$ ) \\
\hline Integration time & $90 \mathrm{~s}$ & $10 \mathrm{~s}$ \\
\hline Radiation (Shortwave and Longwave) & $\begin{array}{l}\text { RRTMG Scheme (Integration timestep = } \\
30 \mathrm{~min} \text { ) }\end{array}$ & $\begin{array}{l}\text { RRTMG Scheme (Integration timestep = } \\
5 \mathrm{~min} \text { ) }\end{array}$ \\
\hline Microphysics & $\begin{array}{l}\text { WRF Single-Moment (WSM) 5-class } \\
\text { scheme }\end{array}$ & Thompson Scheme \\
\hline Atmospheric surface layer & MYNN surface layer & MYNN surface layer \\
\hline Land surface & ORCHIDEE & ORCHIDEE \\
\hline Planetary Boundary Layer (PBL) & MYNN 2.5 level TKE scheme & MYNN 2.5 level TKE scheme \\
\hline Cumulus & Kain-Fritsch scheme & no cumulus scheme is used \\
\hline
\end{tabular}

\section{$147 \quad 2.2$ Methodology}

First, we evaluate the added value of the SWE3 in the spatio-temporal distribution of seasonal mean precipitation

149 and also focus on the altitudinal variations of mean precipitation. We also examine the atmospheric conditions to explain the

150 differences observed in seasonal mean precipitation between the two simulations (Detailed discussion related to this is given

151 in section 3.2). In the second step, we examine the added value of SWE3 in the spatial/altitudinal distribution of the wet-day

152 precipitation frequency and intensity of daily mean precipitation. A wet day is a day with precipitation $\geq 1 \mathrm{~mm}$. We also use

153 the probability density function (PDF) to showcase the overall distribution of daily precipitation intensity, and Kolmogorov-

154 Smirnov (K-S) goodness-of-fit test is used to measures the dissimilarity/distance between the two samples i.e. model and

155 observed precipitation (Chakravarti et al. 1967; Torma et al. 2015; Shahi et al. 2021). The KS distance is defined as the

156 maximum vertical absolute difference between two empirical cumulative distribution functions (ECDFs). The K-S distance

157 varies between zero (perfect overlap between the two distributions) and one (no overlap between the two distributions). It is

158 calculated from the formula:

159

$$
d_{K S}(F, G)=\operatorname{supr}_{t \in R}|F(G)-G(t)|
$$


where $F$ and $G$ are the two ECDFs and supr represents the supremum function (Chakravarti et al. 1967; Torma et al. 2015).

In the final evaluation step, we focus on the representation (spatial/altitudinal) of heavy/extreme precipitation. Basically, we used two climate extreme indices i.e. R95p and Rx1day (Karl et al. 1999; Peterson 2005). The R95p is the 99th percentile of the precipitation, and Rx1day is the highest one-day precipitation amount.

We use the Taylor diagram (Taylor 2001) to assess the performance of both simulations in representing the spatial distribution of precipitation (for all cases/indices). We constructed the Taylor diagram with the results of the spatial Index of Agreement (instead of the spatial correlation coefficient) and normalized standard deviation. Willmott (1982) stated that the correlation coefficient is often a misleading measure of accuracy, and proposed a new skill metric i.e. Index of Agreement (IOA). The IOA is calculated as follows:

$$
I O A=1-\frac{\sum_{i=1}^{n}\left(M_{i}-O_{i}\right)^{2}}{\sum_{i=1}^{n}\left(\left|M_{i}-\bar{O}\right|+\left|O_{i}-\bar{O}\right|\right)^{2}}
$$

where $M$ and $O$ represent the model and observation, respectively. $\bar{O}$ represents the observed mean value and $n$ is the number of total data/grid points. The IOA is bounded between 0 and 1 , where a value close to 1 indicates more efficient forecasting skills.

\section{Results and discussion}

\subsection{Spatio-temporal distribution of seasonal mean precipitation}

In this section, we evaluate the spatial distribution of the simulated 10-year seasonal (DJF, MAM, JJA, and SON) mean precipitation over the Iberian Peninsula (IP). The seasonal mean precipitation of the SWE3 and EUR20 simulations for each season is shown in Figs. 2(a1-a4) and 2(b1-b4), respectively, and the relative bias in seasonal mean precipitation of the SWE3 and EUR20 is estimated against the IBERIA01 [SPREAD] datasets and shown in the Figs. 2(c1-c4) [2(e1-e4)] and 2(d1-d4) [2(f1-f4)], respectively. The difference in seasonal mean precipitation between SPREAD and IBERIA01 at the $3 \mathrm{~km}$ resolution grid is also shown in Figs. 2g1-g4 for each season.

The climatological seasonal mean pattern shows that the highest precipitation occurs over the northwestern and northern regions of the IP in all seasons (Fig. 2). As can be seen from figure 2, the regional to local scales precipitation pattern with maximum precipitation in the mountainous peaks of the study domain has been produced by kilometric-scale simulation (SWE3; a1-a4) compared to the coarser-scale simulation (EUR20; b1-b4) for all four seasons; however, the SWE3 simulation exhibits less precipitation in almost all areas of the IP (including the surrounding oceans) except for hilly 
peaks compared to the EUR20 simulation, and perhaps it may be related to improper lateral boundary conditions (LBCs from EUR20), as it is possible that the LBCs (large-scale forcing fields) used for the SWE3 simulation may already have biases that can propagate in the SWE3 simulation domain. Several studies have shown that the biases existing in the LBCs affect the entire limited-area regional climate models (RCMs) domain (Warner et al. 1997; Rinke and Dethloff 2000; Wu et al. 2005; Diaconescu et al. 2007; Køltzow et al. 2008; Diaconescu \& Laprise 2013; Brisson et al. 2015; Panosetti et al. 2019; Rocheta et al. 2014, 2020; Ahrens \& Leps 2021). In the next section, we have tried to understand all these and provided some dynamical factors. On the other hand, a better representation of the topography of mountainous regions in the SWE3 simulation allows the realistic local mountain-valley circulation and other local-scale processes that lead to a better representation of the precipitation in these areas (Karki et al. 2017).

As can be seen from figure 2, the bias patterns derived from the simulations against/using both observations are more or less similar to each other in terms of variability with slight differences in magnitude at some locations for all seasons. On the other hand, we have also noted that the intensity of precipitation varies slightly between the two observations for all seasons which explains the above-noticed differences, as the SPREAD shows slightly higher precipitation than the IBERIA01 in almost all regions of the IP (Figs. 2g1-g4), and this may be due to the different resolutions of both observed datasets. However, the noticeable differences between the two observations have been observed in the eastern and southern parts of the IP for the DJF and JJA seasons; respectively (Figs. 2g1 \& 2g3).

The SWE3 simulation shows a dry bias of up to $60 \%$ (80\% for the JJA) in observed seasonal mean precipitation especially in the western regions of the IP for all the seasons (Figs. 2c1-c4 \& 2e1-e4), while the EUR20 simulation exhibits relatively low wet precipitation bias over the maximum areas of the western regions of the IP for the MAM and JJA seasons (Figs. 2d2-d3 \& 2f2-f3), and the mixture of dry and wet precipitation biases are observed in these areas for SON and DJF seasons (Figs. 2d4-d1 \& 2f4-2f1). On the other hand, the SWE3 simulation slightly overestimates the observed seasonal mean precipitation in some parts of the mountainous ranges of the IP for the MAM and SON seasons, whereas in the DJF season, overestimation of precipitation is noted only in the peaks of the mountains ranges. For the JJA season, the SWE3 substantially underestimates the observed mean precipitation over eastern parts of the IP and overestimates the precipitation over the south-central parts of the IP and also in some parts of the central and northern plateau mountainous regions of the IP. Due to the sparse station density in the mountainous regions, there is a larger uncertainty in the observational dataset in these regions, which may explain the bias of mountainous regions in the simulations. The bias pattern of SWE3 is quite similar to the bias pattern of EUR20 in the central parts of the IP for all seasons and it is most likely that it inherited from the driving EUR20 simulation. From the above discussion, It can be concluded that the SWE3 simulated more dry bias in 
more areas of the IP compared to the EUR20, and severely underestimated the observed mean precipitation especially over the western parts of the IP.

We have also calculated the annual cycle of area-averaged monthly mean precipitation over the Spain landmass (over the area of SPREAD) and shown in Fig. 3. It can be clearly seen from figure 3 that the SWE3 simulation underestimates the observed mean precipitation of each month, while the EUR20 simulation is in agreement with the observed monthly mean precipitation, except in the fall (Fig. 3). The SWE3 simulation underestimates the precipitation by about $0.7 \mathrm{~mm} /$ day in October-March, whereas EUR20 simulated precipitation is much closer to the observations in JanuaryMarch and underestimates the precipitation by about $0.3 \mathrm{~mm} /$ day in October-December (Fig. 3). It is also noted that the SWE3 (EUR20) underestimates (overestimates) the precipitation in April-September (Fig. 3). The impact of resolution on seasonal mean precipitation has also been observed as the SPREAD shows slightly less and high precipitation in JanuarySeptember and October-December as compared to the IBERIA01, respectively (Fig. 3), and therefore we can say that the amount of seasonal mean precipitation can vary with resolution.

For the quantitative analysis, the Taylor diagram (Taylor 2001) is constructed using the spatial Index of Agreement (IOA) and normalized standard deviation (NSD) ratio between observed (i.e. SPREAD and IBERIA01) and simulated seasonal mean precipitation for each season and shown in supplementary Figs. S1a and S1b. Compared to the observed NSD value, the EUR20 shows slightly better performance than the SWE3 in the simulation of the spatial variability of seasonal mean precipitation for each season (Figs. S1a \& S1b). The high IOA value (>=0.79) between the simulated and observed seasonal mean precipitation for each season indicates good quality of the simulation, although the IOA value is higher for the EUR20 than for the SW3 (Figs. S1a \& S1b). Broadly, it can be inferred that EUR20 performed better in simulating seasonal mean precipitation for each season than the SWE3.

From the above discussion, it is clear that SWE3 simulated less seasonal mean precipitation than EUR20 in almost all areas of IP. In the light of the results, which show a noticeable sensitivity of precipitation associated with the mountain ranges, we perform a detailed evaluation focused on the elevation. To do so, the altitudinal variation (with elevation class of $200 \mathrm{~m}$ ) of simulated and observed seasonal mean precipitation for each season is calculated over the Spain subcontinent at both resolutions i.e. downscaled (3 km) and upscaled (20 km) using the topography of the SWE3 and EUR20 simulations, respectively and shown in Fig. 4. The percentage of the total grid points covered by each class in the Spain landmass is also calculated at $3 \mathrm{~km}$ and $20 \mathrm{~km}$ resolutions and shown in the Figs. 4d1 \& 4d2, respectively. The actual number of rain gauge stations presented in the IBERIA01 dataset for each class is also shown in Fig. 4a1. A topographic map with rain gauge stations is not available for the SPREAD data. At the 3km grid, the SWE3 simulation shows less and more mean 
precipitation than the EUR20 for all seasons (except JJA where the SWE3 shows less mean precipitation in all areas) in areas with elevations below and above 1600 m which covers about $97 \%$ and $3 \%$ of the total grid points of the Spain landmass, respectively (Figs. 4a1-d1). At the 20km grid, the SWE3 exhibits less mean precipitation than the EUR20 for the MAM and JJA seasons in all the areas, and in DJF and SON seasons, a slight improvement in mean precipitation is seen in areas with elevations above $1600 \mathrm{~m}$ (Figs. 4a2-d2). It is also noted that both observations show almost the same pattern with slight differences in precipitation magnitude and this difference may be due to different resolutions of both observations

251

252

(Fig. 4). Compared with observations, the EUR20 shows better results in the lowlands areas, while SWE3 is comparable in the higher elevation classes. In the JJA season, the EUR20 is better in all elevation classes. Overall, we have not found added value in the simulation of mean precipitation by the SWE3 in comparison to the parent EUR20 simulation, although, in the high-elevation classes, slight differences in the mean precipitation of both simulations have been observed. However, due to inaccuracies (due to sparse station density) in observational datasets over the mountainous regions, it is difficult to decide which one is accurate. Torma et al. (2015) concluded that in general, the amounts of simulated mean precipitation increase with the resolution, i.e., going from the coarser to finer scale simulations, while we have found the opposite results. Therefore we can say that this can only be true for complex terrain regions like the Alps (Torma et al. 2015), Himalayas (Karki et al. 2017), and also depends on many factors such as the quality of initial- and lateral-BCs, and also on the domain size of the RCM simulations (Warner et al. 1997; Rinke and Dethloff 2000; Wu et al. 2005; Diaconescu et al. 2007; Køltzow et al. 2008; Diaconescu \& Laprise 2013; Brisson et al. 2015; Panosetti et al. 2019; Rocheta et al. 2014, 2020; Ahrens \& Leps 2021).

\subsection{Spatial distribution of mean moisture transport and its convergence}

As we observed in the previous section, the SWE3 simulated less seasonal mean precipitation than EUR20 in almost all regions of the IP, so in this section, we tried to understand the possible dynamical factors responsible for this. In order to understand this, basically, we have calculated the vertically integrated moisture transport (VIMT) and vertically integrated moisture flux convergence (VIMFC). The VIMT and VIMFC have been computed using the moisture budget equation between surface and $300 \mathrm{hPa}$, since most water vapour exists below $300 \mathrm{hPa}$. The mathematical form of these equations can be written as:

$$
V I M F C=-\nabla \cdot \frac{1}{g} \int_{P \text { top }}^{P s f c} q V d p=P-E+\frac{\partial w}{\partial t}
$$

$w=\frac{1}{g} \int_{\text {Ptop }}^{\text {Psfc }} q d p$ 

atmosphere (300 hPa in our case), $V=(u, v)$ is the horizontal wind vector, $P$ is the precipitation rate, $E$ is the or annual time scales, the term $\partial w / \partial t \quad$ can be neglected (Cullather et al. 2000). season is shown in Figs. 5a1-a4 and 5b1-b4; respectively. Similarly, the seasonal mean VIMFC pattern for the SWE3 and EUR20 simulations is shown in the Figs. 6a1-a4 and 6b1-b4; respectively. The spatial pattern of the VIMT and VIMFC clearly highlights the seasonal difference between SWE3 and EUR20 simulations in terms of the magnitude and spatial extent of the large-scale transport of moisture over the IP for all seasons (Figs. 5 and 6). The Atlantic Ocean (with the westerly circulation flow) has been found to be one of the major source of moisture for precipitation over the IP (Gimeno et al. 2010; Gimeno et al. 2012; Şahin et al. 2015). This transport of moisture-laden westerly movement of winds (west-east) from the Atlantic Ocean towards the IP which contributes to the convergence over the IP, can be clearly seen in the EUR20 simulation, and also this pattern is quite persistent for all seasons. However, the slight west-southeast shift in the west-east winds over the Atlantic Ocean has been noted for all seasons except the DJF season, although this signal is more dominant in the JJA season, and this can be associated with the formation of a thermal low-pressure system over the Iberian Peninsula that slightly deviates the westerly flow to the southeast direction (Font 1983; Martín et al. 2001; Hoinka and Castro 2003). The thermal low over the IP is more frequent in summer, but it also occurs in spring and autumn (Font 1983). In summer, the tropical circulation patterns are well known to be associated with southerly and southeasterly warmer wind flows, which dominate over most of the Mediterranean basin, especially in the eastern Mediterranean region (Şahin et al. 2015), and consequently, the southerly blow of winds coming from the southern region towards the northeast direction and its turn to the southeastern direction around the eastern Mediterranean have also been observed, and this resulting pattern is mainly from the northward motion of the inter-tropical convergence zone (ITCZ) and the thermally originated south-Asian monsoon low (Rodwell and Hoskins 1996; Türkeş and Erlat 2006; Şahin et al. 2015), which controls specific humidity over the Mediterranean basin and the land areas around it. 
In the SWE3 simulation, the direction of the wind pattern is significantly different from the EUR20 simulation

299 (Figs. 5 and 6). The first difference is that the westerly circulation pattern is shifted southward in all seasons, although this

shift is observed below $40^{\circ} \mathrm{N}$ in the DJF season. The shift in the wind patterns leads to a decrease in the transport of moisture towards the IP from the Atlantic Ocean, leading to a decrease in precipitation over the IP, particularly in the western region of the IP, and this is also clear from the VIMFC pattern. Apart from the southward shift, a decline in wind strength has also been observed, especially in the western parts of the domain, although the wind strength is slightly higher over the southwestern boundary/border in all seasons except DJF season (wind strength is slightly lower in DJF) and this may be due to the adverse effects of boundary conditions. On the other hand, there is an enhancement of southerly winds (with slightly shifted towards the north) over the Mediterranean basin, and eastern and central regions of the IP has also been observed, which further effectively affects the humidity of these regions as these winds are warm and dry, leading to a decrease in precipitation, and this is also evident from the VIMFC pattern. However, this signal is more prominent in summer and weaker in winter. In the northern region, the northeasterly movement (north-northeast) of winds has been observed instead of the westerly flow (west-east), which explains the decrease in precipitation in these regions. We observed similar results on a $3 \mathrm{~km}$ grid (figures not shown).

Overall, the large-scale transport of moisture patterns obtained from both simulations explains the differences in precipitation of both simulations. The circulation patterns acquired from the EUR20 simulation are consistent with previous studies. On the other hand, the circulation patterns obtained from the SWE3 simulation is quite different from the EUR20 simulation in terms of intensity as well as the direction of the winds, and we also noticed that the differences in circulation patterns start at the boundary of the SWE3 domain for all seasons, therefore, here it appears that the large scale forcing fields and its lateral boundary conditions (LBC)-associated errors are also playing a role in the modulation of winds, as the impact of LBC errors represents an important issue in the RCM simulations (Warner et al. 1997; Rinke and Dethloff 2000; Wu et al. 2005; Diaconescu et al. 2007; Køltzow et al. 2008; Diaconescu \& Laprise 2013; Brisson et al. 2015; Panosetti et al. 2019; Rocheta et al. 2014, 2020; Ahrens \& Leps 2021). Diaconescu \& Laprise (2013) suggested that the RCMs can bring some reduction of errors in large scales when very large domains are used. Additional modeling experiments are needed for a better understanding of these aspects.

\subsection{Spatio-temporal distribution of wet-day precipitation frequency and Intensity}

The spatial distribution of the frequency and intensity of daily mean precipitation (days where the precipitation >= $1 \mathrm{~mm}$ ) is calculated for each season during 2000-2009 for both simulations and observations and shown in Fig. 7. Figures 7a1-a4 (7e1-e4), 7b1-b4 (7f1-f4), 7c1-c4 (7g1-g4), and 7d1-d4 (7h1-h4) show the spatial distribution of the precipitation 
frequency (intensity) obtained from the EUR20, SWE3, IBERIA01, and SPREAD, respectively. We have also calculated the altitudinal variation (similar to Fig. 4) of the frequency and intensity of the wet-day precipitation for each season at both resolutions for quantitative assessment and shown in Figs. 8 and 9, respectively. We have taken only the Spain subcontinent (area of SPREAD) in the altitudinal variation calculation.

We find that the SWE3 simulation significantly reduced the frequency of the wet-day precipitation not only over the land points of the IP but also over the surrounding oceans for all the seasons compared to EUR20 simulation (Figs. 7a1a4 and 7b1-b4), while it produces more intense wet-day precipitation over the IP subcontinent (Figs. 7e1-e4 and 7f1-f4). In general, convection-permitting models tend to produce less frequent but more intense precipitation intensities compared to coarse resolution models (Berthou et al. 2018; Chan et al. 2020; Ban et al. 2021). Moreover, significant differences have also been observed in the magnitude of frequency and intensity of the wet-day precipitation obtained from both observations, as the SPREAD shows less frequent but more intense precipitation than the IBERIA01, and therefore we can say that the frequency and intensity of precipitation vary with resolution (Fig. 7). The above results are also evident from Figs. 8 and 9. On the other hand, the spatial structure of the frequency and intensity of wet-day precipitation derived from the SWE3 (EUR20) shows comparable similarities with respect to the SPREAD (IBERIA01) with slight variations in the magnitude of the frequency and intensity of the wet-day precipitation at some locations for all seasons, respectively and it may be because of the finer and coarser resolutions of the observed products (Fig. 7). A detailed comparison of the obtained simulation results with the observed one is discussed below.

The SWE3 simulation substantially underestimates the observed wet-day frequency obtained from the SPREAD over the northwest corner of the IP, and slightly underestimation is noted in most of the other parts of IP for all seasons (Figs. 7b1-b4 and 7d1-d4), and these results are more pronounced with altitudinal variation (Fig. 8). The altitudinal variation of the wet-day frequency obtained from the SWE3 reflects a slight overestimation of frequency compared to SPREAD for the DJF and MAM seasons in the higher elevation classes, and slightly underestimates the observed frequency of the rest areas for all seasons (Fig. 8). In the JJA season, the model correctly simulated the observed frequency in areas of the lowlands. The EUR20 simulation shows almost the same amount of the wet-day frequency compared to the IBERIA01 for the DJF and SON seasons (Figs. 7a1,a4 and 7c1,c4) with slight overestimation of the frequency in the higher elevation classes (Fig. 8), and notably overestimates the wet-day frequency in the northern parts of the IP for the MAM and JJA seasons (Figs. 7a2,a3 and 7c2,c3) and consequently overestimation of the observed wet-day frequency by the EUR20 is noted in all elevation classes (Fig. 8). Compared with the SPREAD, we find the added value in the simulation of wet-day 
frequency by SWE3 over the parent EUR20, while the performance of the SWE3 deteriorates when compared with IBERIA01.

It can be clearly seen that the finer-scale spatial variability with peaks in the mountainous regions of the observed wet-day intensity is relatively well captured by the SWE3 (Fig. 7). The EUR20 simulation significantly underestimates the wet-day intensity in almost all regions of the IP as compared to both observations for all seasons, although the maximum difference in wet-day intensity has been observed with the SPREAD (Fig. 7) and can also be seen clearly from the Fig. 9. The SWE3 simulates more intense wet-day precipitation than the EUR20 in almost all regions of the IP for all seasons (Fig. 7) however, we have not observed much difference in the precipitation of lowlands areas (in areas below $600 \mathrm{~m}$ for JJA season and $200 \mathrm{~m}$ for the rest of the season) between the two simulations for all seasons (Fig. 9). Compared to the IBERIA01, the SWE3 simulation overestimates the wet-day precipitation in most areas of the IP, except that it shows an underestimation of precipitation in some areas in the northwest corner and Mediterranean coasts of southwest and eastern Spain for all the seasons (Figs. 7f1-f4 and 7g1-g4). It is also clear from figure 9 that the SWE3 simulation slightly underestimates the observed (IBERIA01) wet-day precipitation of lowland areas (in areas below $600 \mathrm{~m}$ for DJF season and $400 \mathrm{~m}$ for the rest of the season) and overestimates the observed precipitation in the rest of areas for all the seasons. While compared to the SPREAD, the SWE3 simulation underestimates the wet-day precipitation in almost all regions of the IP for all the seasons, although some overestimation of precipitation is noted in the northern and southern plateau regions of the IP for the MAM season and western parts of the Pyrenees for the DJF season (Figs. 7f1-f4 and 7h1-h4). It can also be seen from figure 9 that the SWE3 simulation underestimates the observed (SPREAD) wet-day precipitation of all altitude classes for JJA and SON seasons and slightly overestimates the observed precipitation of mountainous regions for the DJF and MAM seasons, and also we have not seen much difference in wet-day precipitation between the SWE3 and SPREAD for the MAM season in areas with elevations of more than $400 \mathrm{~m}$ (Fig. 9). Overall, the added value in the SWE3 simulation is found in the reproduction of wet-day intensity as compared to the EUR20 for all seasons.

For the quantitative assessment of simulation performance, the Taylor diagram is produced using the spatial IOA and NSD ratio between observed and simulated frequency and intensity of the wet-day precipitation for each season and shown in supplementary Fig. S2. It is clear from the IOA value that the spatial pattern of the wet-day frequency and intensity of the SPREAD (IBERIA01) are better represented by SWE3 (EUR20) than the EUR20 (SWE3) except for the case of the wet-day intensity of the IBERIA01 for the DJF season where the SWE3 exhibits a higher IOA value than the EUR20 (Fig. S2). It is also noted that the EUR20 overestimates the spatial variability (NSD) of the observed wet-day frequency for all seasons, while the SWE3 underestimates it (Figs. S2a and S2c). The spatial variability of the wet-day 
frequency of the SPREAD (IBERIA01) is captured quite well by the EUR20 than the SWE3 for the DJF season (DJF-MAM seasons), and the SWE3 shows better skill in simulating the observed spatial variability compared to the EUR20 for the rest of the season (Fig. S2a and S2c). The SWE3 shows better skill in predicting the observed spatial variability of the wet-day intensity than the EUR20 for all the seasons (Figs. S2b and S2d), although SWE3 notably underestimates the observed (SPREAD) spatial variability of the wet-day intensity (Fig. S2b).

In summary, SWE3 simulated less frequent but more intense wet-day precipitation intensities compared to EUR20 and it is consistent with previous studies (Chan et al. 2020; Ban et al. 2021). We have also found a large difference in the intensity and frequency of wet-day precipitation between the two observations, as the SPREAD showed less frequent but more intense precipitation compared with the IBERIA01, and the SWE3 (EUR20) simulation showed a good similarity with the observed SPREAD (IBERIA01), and it highlights the importance of having high-resolution good quality observed datasets for regional-to-local scale assessments. One thing is clear (with the observational evidence) from the above discussion that the higher resolution datasets have less frequent but more intense wet-day precipitation intensities compared to the coarser resolution datasets, and also point towards the need of the high-resolution good quality of observational datasets for good estimation.

\subsection{Probability distribution of daily mean precipitation}

So far we have noted that the SWE3 simulated less seasonal mean precipitation as compared to the EUR20 as well as the observations. It has also been noted the significant differences in the wet-day frequency and intensity of both simulations as well as in the observations. However, differences in precipitation amounts and comparative results have been observed for the lowlands and mountainous regions. So for a better view and for the better comparison of the magnitude of the precipitation of lowlands and mountainous regions at each grid cell, we have classified the total area of the Spain landmass into two elevation classes, which is low (area between the altitudes of $>=0$ and $<=1000$ m; which covers about $82 \%$ of the total grid points) and high (area above the altitudes of $1000 \mathrm{~m}$; which covers about $18 \%$ of the total grid points) and we computed the PDFs of the daily mean precipitation for each category for all seasons at $3 \mathrm{~km}$ [20km] resolution grids and shown in the Figs. 10(a-d) [supplementary: S3(a-d)] and 11(a-d) [supplementary: S4(a-d)], respectively. The PDFs of daily mean precipitation for the lowlands and mountainous regions at both grids clearly reveal the added value of the finescale simulation over the coarse-scale simulation for all seasons. The significant differences in the PDFs tails of both observations are also observed for all seasons, and it may be due to the different resolution of both datasets as we earlier discussed. 

IBERIA01 than the SPREAD with slightly underestimations of the low- to moderate-intensity tails of the IBERIA01 for the DJF season (Fig. 10a). For the MAM and SON seasons, the tail of the SWE3 is in between the tails of the two observations with slightly underestimations of the low and high intensity tails of the IBERIA01 and SPREAD; respectively and notably underestimations and overestimations of the low- to moderate-intensity and moderate- to high- intensity tails of the SPREAD and IBERIA01; respectively (Figs. 10b \& 10d). For the JJA season, the SWE3 run slightly overestimates and underestimates the low intensity events (<=35mm/day) of the IBERIA01 and SPREAD; respectively and significantly and slightly overestimates the occurrence of medium- to high-intensity events of the IBERIA01 and SPREAD; respectively (Fig. 10c). It is also noted that the SWE3 underestimates the frequency of occurrence of the intense extreme events of the SPREAD for all the seasons except for the JJA season, where the SWE3 shows an overestimation (Fig. 10). In the mountainous region at $3 \mathrm{~km}$ grid (Fig. 11), the SWE3 tail is in between the two observations and more in line with the tail of the SPREAD than the IBERIA01 for all the seasons except for the low intensity tail ( $<=20 \mathrm{~mm} /$ day) of the JJA season, where the SWE3 shows underestimation of precipitation intensity with both observations (Fig. 11). The SWE3 underestimates the tail of the SPREAD for all the seasons except for the MAM season where the SWE3 tail corresponds to the tail of the SPREAD, although the underestimation is larger for the DJF season (Fig. 11). We have also noted that the SWE3 underestimates the frequency of occurrence of the high-intensity events of the SPREAD for all seasons except for the MAM season (Fig. 11). In the mountainous region at $3 \mathrm{~km}$ grid, we have noted maximum differences not only in the moderate- to high- intensity tails of both observations but also in the moderate- to high- intensity tails of both simulations for all seasons (Fig. 11). However, since the observational rain gauge network stations are very sparse over the higher mountainous areas (e.g. Pyrenees, Baetic, Cantabrian mountains, etc. of the IP) thereby having considerable uncertainties in measurements/estimation of excessive rainfall as well, particularly for studying extreme events, so it is difficult to determine which estimation (observation or model) is correct for the higher mountainous regions. It is clear from the above discussion that the maximum added value of the fine-scale simulation over the driving coarse-scale simulation is found in the mountainous region.

The PDFs of the upscaled daily mean precipitation for the lowlands and mountainous regions at the coarser resolution grid $(20 \mathrm{~km})$ clearly illustrate the added value of the SWE3 over the EUR20 in the occurrence of the moderate- to high- intensity events and the tail of SWE3 is closer to the tail of the observations than to the EUR20, while it worsens the results in the case of the low-intensity events as compared to observations for all the seasons (Figs. S3 \& S4). In the lowlands regions at 20km grid, the moderate- to high- intensity tails of the SWE3 lies between the tails of both observations 
441

442

443

444

445

for the JJA season, and the SWE3 underestimates the observed tails for the rest of the season, however, this underestimation is very less with the IBERIA01 than with the SPREAD (Fig. S3). In the mountainous region at the upscaled grid, the moderate- to high-intensity tails of the SWE3 lies between the tail of the IBERIA01 and the SPREAD for all seasons, although the SWE3 slightly underestimates and overestimates the occurrence of the high-intensity events of the IBERIA01 and the SPREAD; respectively (Fig. S4).

In summary, we have found that the significant added value in the simulation of moderate- to high- intensity events of the daily precipitation by the SWE3 compared to the driving EUR20, not only at the downscaled finer-scale grids but also when the datasets are upscaled at the coarser-scale grids. However, the maximum added value is seen in the mountainous region at both grids. We have also observed notable differences in the tails of the distribution of both observations, and the simulated PDFs are comparable with the observed PDFs.

For more quantitative analysis, we have also computed the point-wise K-S distance between the simulated and observed empirical cumulative distribution functions (ECDFs) of the daily precipitation for each season during 2000-2009 at both resolution grids i.e. $3 \mathrm{~km}$ and $20 \mathrm{~km}$ and shown in the Figs. 12 and S5 (supplementary), respectively. Figures 12a1a4 (12c1-c4) and 12b1-b4 (12d1-d4) show the statistics obtained from the SWE3 and EUR20 using IBERIA01 (SPREAD) observation for each season at the $3 \mathrm{~km}$ resolution, respectively. Similarly, supplementary figure S5 shows the statistics obtained at the $20 \mathrm{~km}$ resolution grid. With the IBERIA01, the KS distance is higher for the SWE3 than the EUR20, while with the SPREAD, the distance is lower for the SWE3 than the EUR20 in almost all over the study domain for each season at both resolution grids (Figs. 12 \& S5), and it points towards the importance of observed resolution datasets in the comparison of the model simulated outputs. In other words, the added value of SWE3 over the driving EUR20 is obtained with the SPREAD in the representation of KS distance, while with the IBERIA01, SWE3 performance is worse than EUR20 and it may be due to the coarser resolution of the IBERIA01 datasets (Figs. 12 \& S5). From the above discussion, it is clear that the KS distance of both simulations varies with the observed resolution, for example, the SWE3 produces the lower value of the KS distance with the SPREAD than IBERIA01 and the opposite is true in the case of the EUR20, and it is likely due to the fact that the tail of the distribution varies with resolution and that can be clearly seen from the PDFs plots. It can also be suggested from the above discussion that the model simulated datasets must be compared with the same or nearly identical resolution observational datasets for better estimation, and also interpolating the dataset has no effect on the actual conclusion.

\subsection{Spatio-temporal distribution of heavy/extreme precipitation}


To examine the added value of the fine-scale simulation over the driving coarser-scale simulation in the simulation of heavy/extreme precipitation, we have computed the 99th percentile (R95p) of the daily mean precipitation and highest one-day precipitation amount (Rx1day) in this section, and the obtained results are shown in figure 13. Figures a1-a4 (e1e4), b1-b4 (f1-f4), c1-c4 (g1-g4), and d1-d4 (h1-h4) show the spatial distribution of the Rx1day (R95p) for the EUR20, SWE3, IBERIA01, and SPREAD, respectively. The regional to local scales precipitation pattern with clear added value in the SWE3 simulation is observed in the representation of extreme precipitation as compared to the EUR20 for both metrics for all seasons (Fig. 13). It has also been observed that both observations show almost similar precipitation patterns in terms of spatial variability, although some differences in precipitation magnitudes have been noted (Fig. 13). It can be also seen from Fig. 13 that the SWE3 simulation captures the observed precipitation pattern to a great extent, however, there are some biases in the precipitation magnitude at some places, particularly in the southwestern and northwestern regions of Spain and the Mediterranean coasts, but here, we must also take into account the observational uncertainties in the estimation/representation of extreme precipitation events.

For more quantitative assessment, we computed the altitudinal variation (similar to Fig. 4) of the R95p and Rx1day for each season at both resolutions and shown in supplementary Figs. S6 and S7, respectively. It can be seen from the figure that the km-scale simulation shows a clear improvement over the coarse-resolution simulation in the representation of extreme precipitation in almost all the altitudinal classes for all seasons at both grids. However, in the case of R95p, the SWE3 simulated slightly less precipitation than the EUR20 in areas $<=200 \mathrm{~m}$ for MAM \& SON seasons, areas $<=400 \mathrm{~m}$ for JJA, and areas $<=600 \mathrm{~m}$ for DJF. On the other hand, differences in the precipitation magnitude of both observations have also been observed in both cases (R95p and Rx1day), although this difference is larger for higher elevation classes (Figs. S6 \& S7). Furthermore, we noted that the SWE3 simulation underestimates the observed R95p precipitation in lowlands areas and shows a good agreement with observations for the higher elevation classes with slight variation in the magnitude of the precipitation (Fig. S6). In the case of Rx1day, the SWE3 is in agreement with the observed precipitation for all elevation classes with slight variation in the precipitation magnitude (Fig. S7). Overall, these results demonstrate a clear advantage of km-scale simulations in the representation of high-impact precipitation events.

In quantitative terms (Taylor diagram), it is clear from the high IOA value between simulation and observation that the predictive skill of the simulation is greater in the representation of observed extreme precipitation patterns (supplementary Fig. S8). It has also been noted that the IOA value is higher for the R95p than the Rx1day. The SWE3 shows better results than the EUR20 in the representation of the observed (SPREAD) spatial variability of both extreme indices for all seasons, although we have not seen much difference in the IOA value obtained from both simulations for all 
seasons except JJA, where the EUR20 reflects higher IOA value than the SWE3 (Figs. S8a \& S8b). On the other hand, the EUR20 shows a higher IOA value than the SWE3 for the MAM and JJA seasons with the IBERIA01, and we have not seen much difference in the IOA value for the remaining two seasons (Figs. S8c \& S8d). In the case of R95p, the SWE3 simulated NSD value is closer to the observed one (IBERIA01) for all seasons except JJA, while in the case of Rx1day, the SWE3 (EUR20) simulated NSD value is closer to the observed one for DJF-SON (MAM-JJA) seasons (Figs. S8c \& S8d).

\section{Summary and Conclusions}

The aim of this study is to evaluate the added value of the convection-permitting simulation ( $3 \mathrm{~km}$, SWE3) compared to the driving coarser-resolution parameterized convection simulation (20 km, EUR20) in the representation of the spatio-temporal pattern of the observed mean and extreme precipitation over the Iberian Peninsula (IP) for all four seasons (i.e. Winter, Spring, Summer, and Autumn) during 2000-2009. Both simulations are performed with the recently developed RegIPSL regional earth system model in the frame of the EUCP H2020 project and CORDEX. The coarser-scale simulation (20 km grid) is forced by the 6-hourly ERA-Interim ( $0.75^{\circ}$ resolution) initial and lateral boundary conditions (IC-LBCs), while the finer-scale simulation (3km grid) is driven by the 3-hourly coarser-scale simulated IC-LBCs. The model results are evaluated against two available high-resolution daily gridded observational datasets i.e. SPREAD (5 km grid) and IBERIA01 (10 km grid), and we have also compared the results obtained from the two observations.

No clear benefit/added-value of the convection-permitting simulation has been found in the reproduction of observed seasonal mean precipitation of the Iberian Peninsula except the spatial variation over hilly peaks compared to coarse-scale simulation for all seasons. The observed spatio-temporal pattern and variability of the seasonal mean precipitation are quantitatively better represented by the EUR20 than the SWE3 simulation. The km-scale simulation substantially underestimates the observed seasonal mean precipitation especially over the western parts of the IP compared to the EUR20 simulation which explains that on average over the whole IP. The SWE3 simulation shows a southward shift of the westerly winds at the western side of the Iberian peninsula compared to the EUR20 simulation, reflecting/indicating a decrease in moisture transport from the Atlantic Ocean towards the IP leading to a decrease in the precipitation. Additionally, the escalation of southerly winds over the IP has also been observed, bringing warm and dry air which further affects moisture transport effectively, leading to a decrease in precipitation. We speculate that the changes in the behavior of circulation patterns in the SWE3 simulation probably attribute to either poor representation of lateral boundary conditions (LBCs) or poor selection of domain or poor land-surface initialization. Several hypothesis-driven modeling experiments are needed to better understand these results. It would be interesting to first see the behavior of the convection-permitting simulation by running the model with a larger domain size but that would require significant computational resources/costs. 
The clear improvement of kilometric-scale simulation over the driving coarser-scale simulation has been found in the representation of the spatio-temporal distribution of the Kolmogorov-Smirnov (K-S) distance, wet-day precipitation frequency and intensity, and also in the reproduction of the heavy precipitation events for each season at both resolutions i.e. downscaled and upscaled. On the other hand, it has also been noted that the spatio-temporal distribution of precipitation for all metrics used varies between the two observational datasets for all seasons, although differences are weaker in the case of the seasonal mean precipitation and larger/notable for the wet-day precipitation frequency and intensity and also for the case of the extreme precipitation events. In quantitative terms, the SPREAD shows less frequent but more intense wet-day precipitation and more intense extreme precipitation amounts than the IBERIA01, and this variation may be due to the different resolutions of the observational datasets, and it also highlights the importance of having high-resolution goodquality observed datasets for regional-to-local scale assessments. Also, we have observed that the km-scale simulated results are more comparable and closer to the SPREAD than the IBERIA01 and the opposite is true in the case of coarser-scale simulation, which emphasizes the fact that the model simulated precipitation should be compared with similar or nearly identical resolution observational datasets for better evaluation/estimation. It is likely true that we should use the SWE3 simulation to study high-impact weather events because of the intensity of the events. On the other hand, in the mountainous/hilly regions, it is difficult to determine which estimate is correct because observational rain gauge network stations in these areas are very sparse, leading to considerable uncertainty in the measurement of the precipitation.

These results demonstrate a clear advantage of using a RegIPSL model at the kilometric-scale over the Iberian Peninsula in the simulation for high-impact weather events, consistently with previous studies over other areas, and also point towards the need of the very high-resolution good-quality of observational datasets for the accurate evaluation of model-simulated results.

\section{Acknowledgements}

This research was supported/funded by the HORIZON 2020 EUCP (European Climate Prediction system) project (https://www.eucp-project.eu/), under grant agreement No. 776613. Simulations were performed on the French national centre Institut du développement et des ressources en informatique scientifique (IDRIS) with granted access to the high performance computing (HPC) resources under the allocation A0070100227 made by Grand équipement national de calcul intensif (GENCI). We also thank the Institut Pierre Simon Laplace (IPSL) mésocentre Ensemble de Services Pour la Recherche à l'IPSL (ESPRI) for providing assistance, storage, and computing resources. 


\section{Declarations:}

557 Funding: This work was supported by the HORIZON 2020 EUCP (European Climate Prediction system) project

558 (https://www.eucp-project.eu/), under grant agreement No. 776613.

559 Conflicts of interest/Competing interests: The authors declare that they have no conflict of interest.

560 Availability of data and material: The datasets used in this work are available on request from the corresponding author.

561 Code availability: The analysis codes are available on request from the corresponding author.

562

563

564

565

566

567

568

569

570

571

572

573

574

575

576

577

578

579

580

581

582

583

584 
586 Ahrens B, Leps N (2021) Sensitivity of Convection Permitting Simulations to Lateral Boundary Conditions in Idealised 587 Experiments. Earth and Space Science Open Archive ESSOAr. https://doi.org/10.1002/essoar.10506295.1

588 Ban N, Caillaud C, Coppola E et al (2021) The first multi-model ensemble of regional climate simulations at kilometer589 scale resolution, part I: evaluation of precipitation. Clim Dyn. https://doi.org/10.1007/s00382-021-05708-w

590 Bechtold P, Chaboureau J-P, Beljaars A, Betts AK, Kohler M, Miller M, Redelsperger J-L (2004) The simulation of the 591 diurnal cycle of convective precipitation over land in a global model. Q J R Meteorol Soc 130:3119-3137. 592 https://doi.org/10.1256/qj.03.103

593 Berthou S, Kendon E, Chan S, Ban N, Leutwyler D, Schar C, Fosser G (2018) Pan-European climate at convection594 permitting scale: a model intercomparison study. Clim Dyn 55:35-59. https://doi.org/10.1007/s00382-018-4114-6

595 Brisson E, Demuzere M, van Lipzig NP (2015) Modelling strategies for performing convection-permitting climate 596 simulations. Meteorol Z 25(2):149-163. https://doi.org/10.1127/metz/2015/0598

597 Brisson E, Van Weverberg K, Demuzere M, Devis A, Saeed S, Stengel M, van Lipzig NP (2016) How well can a 598 convection-permitting climate model reproduce decadal statistics of precipitation, temperature and cloud characteristics? 599 Clim Dyn 47(9-10):3043-3061. https://doi.org/10.1007/s00382-016-3012-z

600 Brockhaus P, Lüthi D, Schär C (2008) Aspects of the diurnal cycle in a regional climate model. Meteorol Z 17:433-443. 601 https://doi.org/10.1127/0941-2948/2008/0316

602 Broucke SV, Wouters H, Demuzere M, van Lipzig NP (2019) The influence of convection-permitting regional climate 603 modeling on future projections of extreme precipitation: dependency on topography and timescale. Clim Dyn 52(9):5303604 5324. https://doi.org/10.1007/s00382-018-4454-2

605 Chakravarty IM, Laha RG, Roy J (1967) Handbook of methods of applied statistics, Volume I. John Wiley and Sons, 606 Hoboken, NJ, pp 392-394

607 Chan SC, Kendon EJ, Berthou S, Fosser G, Lewis E, Fowler HJ (2020) Europe-wide precipitation projections at convection 608 permitting scale with the Unified Model. Clim Dyn 55:409-428. https://doi.org/10.1007/s00382-020-05192-8

609 Chang W, Wang J, Marohnic J, Kotamarthi VR, Moyer EJ (2020) Diagnosing added value of convection-permitting regional 610 models using precipitation event identification and tracking. Clim Dyn 55(1):175-192. https://doi.org/10.1007/s00382-018$611 \quad 4294-0$ 
612 Coppola E, Sobolowski S, Pichelli E, Raffaele F, Ahrens B, Anders I, Ban N, Bastin S, Belda M, Belusic D et al (2020) A

613 first-of-its-kind multi-model convection permitting ensemble for investigating convective phenomena over Europe and the

614 Mediterranean. Clim Dyn 55:3-34. https://doi.org/10.1007/s00382-018-4521-8

615 Cullather RI, Bromwich DH, Serreze MC (2000) The atmospheric hydrologic cycle over the Arctic basin from reanalysis.

616 Part I: comparison with observation and previous studies. J Clim 13:923:937. https://oi.org/10.1175/1520-

617 0442(2000)013\%3C0923:TAHCOT\%3E2.0.CO;2

618 Dee DP, Uppala SM, Simmons AJ et al (2011) The ERA-Interim reanalysis: configuration and performance of the data 619 assimilation system. Q J R Meteorol Soc 137:535-597. https://doi.org/10.1002/qj.828

620 Déqué M, Rowell MP, Lüthi D, Giorgi F, Christensen JH, Rockel B, Jacob D, Kjellström E, de Castro M, van den Hurk B 621 (2007) An intercomparison of regional climate simulations for Europe: assessing uncertainties in model projections. Clim 622 Change 81:53-70. https://doi.org/10.1007/s10584-006-9228-x

623 Diaconescu EP, Laprise R (2013) Can added value be expected in RCM-simulated large scales? Clim Dyn 41(7):1769-1800.

624 https://doi.org/10.1007/s00382-012-1649-9

625 Diaconescu EP, Laprise R, Sushama L (2007) The impact of lateral boundary data errors on the simulated climate of a 626 nested regional climate model. Clim Dyn 28(4):333-350. https://doi.org/10.1007/s00382-006-0189-6

627 Fita L, Polcher J, Giannaros TM, Lorenz T, Milovac J, Sofiadis G, Katragkou E, Bastin S (2019) CORDEX-WRF v1.3: 628 development of a module for the Weather Research and Forecasting (WRF) model to support the CORDEX community. 629 Geosci Model Dev 12(3):1029-1066. https://doi.org/10.5194/gmd-12-1029-2019

630 Font I (1983) Climatología de España y Portugal (Climate of Spain and Portugal). Inst Nacional de Meteorología. 631 Ministerio de Transportes y Comunicaciones de Madrid, pp 296

632 Fosser G, Khodayar S, Berg P (2015) Benefit of convection permitting climate model simulations in the representation of 633 convective precipitation. Clim Dyn 44:45-60. https://doi.org/10.1007/s00382-014-2242-1

634 Frei C, Christensen JH, Dèquè M, Jacob D, Jones RG, Vidale PL (2003) Daily precipitation statistics in regional climate 635 models: evaluation and intercomparison for the European Alps. J Geophys Res Atmos 108:4124. 636 https://doi.org/10.1029/2002JD002287

637 Fumière Q, Déqué M, Nuissier O, Somot S, Alias A, Caillaud C, Laurantin O, Seity Y (2019) Extreme rainfall in 638 Mediterranean France during the fall: added-value of the CNRM-AROME Convection-Permitting Regional Climate Model. 639 Clim Dyn 55:77-91. https://doi.org/10.1007/s00382-019-04898-8 
640 Gimeno L, Nieto R, Trigo RM, Vicente-Serrano SM, López-Moreno JI (2010) Where does the Iberian Peninsula moisture

641 come from? An answer based on a Lagrangian approach. J Hydrometeorol 11:421-436.

642 https://doi.org/10.1175/2009JHM1182.1

643 Gimeno L, Stohl A, Trigo RM, Dominguez F, Yoshimura K, Yu L, Drumond A, Durán-Quesada AM, Nieto R (2012)

644 Oceanic and terrestrial sources of continental precipitation. Rev Geophys 50(4):RG4003.

645 https://doi.org/10.1029/2012RG000389

646 Helsen S, van Lipzig NP, Demuzere M, Broucke SV, Caluwaerts S, De Cruz L, De Troch R, Hamdi R, Termonia P, Van

647 Schaeybroeck B, Wouters H (2020) Consistent scale-dependency of future increases in hourly extreme precipitation in two

648 convection-permitting climate models. Clim Dyn 54(3):1267-1280. https://doi.org/10.1007/s00382-019-05056-w

649 Herrera S, Cardoso RM, Soares PM, Espírito-Santo F, Viterbo P, Gutiérrez JM (2019) Iberia01: a new gridded dataset of 650 daily precipitation and temperatures over Iberia. Earth Syst Sci Data 11:1947-1956. https://doi.org/10.5194/essd-11-19476512019

652 Hohenegger C, Brockhaus P, Schär C (2008) Towards climate simulations at cloud-resolving scales. Meteorol Z 17(4):383653 394. https://doi.org/10.1127/0941-2948/2008/0303

654 Hoinka KP, Castro MD (2003) The Iberian peninsula thermal low. Quarterly Journal of the Royal Meteorological Society: Q 655 J R Meteorol Soc 129(590):1491-1511. https://doi.org/10.1256/qj.01.189

656 Karki R, Gerlitz L, Schickhoff U, Scholten T, Böhner J (2017) Quantifying the added value of convection-permitting 657 climate simulations in complex terrain: a systematic evaluation of WRF over the Himalayas. Earth Syst Dynam 8:507-528.

658 https://doi.org/10.5194/esd-8-507-2017

659 Karl TR, Nicholls N, Ghazi A (1999) CLIVAR/GCOS/WMO workshop on indices and indicators for climate extremes. Clim 660 Change 42:3-7. https://doi.org/10.1023/A:1005491526870

661 Kendon EJ, Ban N, Roberts NM, Fowler HJ, Roberts MJ, Chan SC, Evans JP, Fosser G, Wilkinson JM (2017) Do 662 convection-permitting regional climate models improve projections of future precipitation change? Bull Am Meteor Soc 663 98(1):79-93. https://doi.org/10.1175/BAMS-D-15-0004.1

664 Kendon EJ, Prein AF, Senior CA, Stirling A (2021) Challenges and outlook for convection-permitting climate modelling. 665 Phil Trans R Soc A 379:20190547. https://doi.org/10.1098/rsta.2019.0547

666 Kendon EJ, Roberts NM, Senior CA, Roberts MJ (2012) Realism of rainfall in a very high-resolution regional climate 667 model. J Clim 25(17):5791-5806. https://doi.org/10.1175/JCLI-D-11-00562.1 
Kendon EJ, Stratton RA, Tucker S, Marsham JH, Berthou S, Rowell DP, Senior CA (2019) enhanced future changes in wet and dry extremes over Africa at convection-permitting scale. Nat Commun 10:1794. https://doi.org/10.1038/s41467-01909776-9

Knist S, Goergen K, Simmer C (2020) Evaluation and projected changes of precipitation statistics in convection-permitting WRF climate simulations over Central Europe. Clim Dyn 55:325-341. https://doi.org/10.1007/s00382-018-4147-x

Køltzow M, Iversen T, Haugen JE (2008) Extended Big-Brother experiments: the role of lateral boundary data quality and size of integration domain in regional climate modelling. Tellus A 60(3):398-410. https://doi.org/10.1111/j.16000870.2007.00309.x

Kouadio K, Bastin S, Konare A, Ajayi VO (2020) Does convection-permitting simulate better rainfall distribution and extreme over Guinean coast and surroundings?. Clim Dyn 55(1):153-174. https://doi.org/10.1007/s00382-018-4308-y

Krinner G, Viovy N, de Noblet-Ducoudré N, Ogée J, Polcher J, Friedlingstein P, Ciais P, Sitch S, Prentice IC (2005) A dynamic global vegetation model for studies of the coupled atmosphere-biosphere system. Global Biogeochem Cycles 19(1):GB1015. https://doi.org/10.1029/2003GB002199

Leutwyler D, Lüthi D, Ban N, Fuhrer O, Schär C (2017) Evaluation of the convection-resolving climate modeling approach on continental scales. J Geophys Res Atmos 122(10):5237-5258. https://doi.org/10.1002/2016JD026013

Li P, Furtado K, Zhou T, Chen H, Li J (2021) Convection-permitting modelling improves simulated precipitation over the central and eastern Tibetan Plateau. Q J R Meteorol Soc 147(734):341-362. https://doi.org/10.1002/qj.3921

Li P, Guo Z, Furtado K, Chen H, Li J, Milton S, Field PR, Zhou T (2019) Prediction of heavy precipitation in the eastern China flooding events of 2016: Added value of convection-permitting simulations. Q J R Meteorol Soc 145(724):33003319. https://doi.org/10.1002/qj.3621

Lind P, Belušić D, Christensen OB, Dobler A, Kjellström E, Landgren O, Lindstedt D, Matte D, Pedersen RA, Toivonen E, Wang F (2020) Benefits and added value of convection-permitting climate modeling over fenno-scandinavia. Clim Dyn 55(7):1893-1912. https://doi.org/10.1007/s00382-020-05359-3

Lind P, Lindstedt D, Kjellström E, Jones C (2016) Spatial and temporal characteristics of summer precipitation over central Europe in a suite of high-resolution climate models. J Clim 29(10):3501-3518. https://doi.org/10.1007/s00382-018-4114-6 Liu C, Ikeda K, Rasmussen R, Barlage M, Newman AJ, Prein AF, Chen F, Chen L, Clark M, Dai A, Dudhia J, Eidhammer T, Gochis D, Gutmann E, Kurkute S, Li Y, Thompson G, Yates D (2017) Continental-scale convection-permitting modeling of the current and future climate of North America. Clim Dyn 49(1):71-95. https://doi.org/10.1007/s00382-016-3327-9 
696

697

698

699

700

701

702

703

704

705

706

707

708

709

710

711

712

713

714

715

716

717

718

719

720

721

722

723

724

Lundquist J, Hughes M, Gutmann E, Kapnick S (2020) Our skill in modeling mountain rain and snow is bypassing the skill of our observational networks. Bull Am Meteorol Soc 100(12):2473-2490. https://doi.org/10.1175/BAMS-D-19-0001.1

Madec G, Delecluse P, Imbard M, Levy C (1998) Opa 8 ocean general circulation model - reference manual. Tech rep LODYC/IPSL Note 11.

Martín F, Crespí SN, Palacios M (2001) Simulations of mesoscale circulations in the center of the Iberian Peninsula for thermal low pressure conditions. Part I: Evaluation of the topography vorticity-mode mesoscale model. J Appl Meteorol 40(5):880-904. https://doi.org/10.1175/1520-0450(2001)040\%3C0880:SOMCIT\%3E2.0.CO;2

Meredith E, Maraun D, Semenov V, Park W (2015) Evidence for added value of convection permitting models for studying changes in extreme precipitation. J Geophys Res Atmos 120:12500-12513. https://doi.org/10.1002/2015JD024238

Panosetti D, Schlemmer L, Schär C (2019) Bulk and structural convergence at convection-resolving scales in real-case simulations of summertime moist convection over land. Q J R Meteorol Soc 145(721):1427-1443. https://doi.org/10.1002/qj.3502

Peterson TC (2005) Climate change indices. WMO Bull 54(2):83-86

Prein AF, Langhans W, Fosser G, Ferrone A, Ban N, Goergen K, Keller M, Tölle M, Gutjahr O, Feser F, Brisson E, Kollet S, Schmidli J, van Lipzig NPM, Leung R (2015) A review on regional convection-permitting climate modeling: demonstrations, prospects, and challenges. Rev Geophys 53(2):323-361. https://doi.org/10.1002/2014RG000475

Randall DA, Wood RA, Bony S, Colman R, Fichefet T, Fyfe J, Kattsov J, Pitman A, Shukla J, Srinivasan J, Stouffer RJ, Sumi A, Taylor KE (2007) Cilmate models and their evaluation. In: Solomon S, Qin D, Manning M, Chen Z, Marquis M, Averyt KB, Tignor M, Miller HL (eds) Climate change 2007: the physical science basis Contribution of working group I to the fourth assessment report of the intergovernmental panel on climate change. Cambridge University Press, Cambridge Rasmussen KL, Prein AF, Rasmussen RM, Ikeda K, Liu C (2020) Changes in the convective population and thermodynamic environments in convection-permitting regional climate simulations over the United States. Clim Dyn 55(1):383-408. https://doi.org/10.1007/s00382-017-4000-7

Rinke A, Dethloff K (2000) On the sensitivity of a regional Arctic climate model to initial and boundary conditions. Clim Res 14:101-113. https://doi.org/10.3354/cr014101

Rocheta E, Evans JP, Sharma A (2014) Assessing atmospheric bias correction for dynamical consistency using potential vorticity. Environ Res Lett 9(12):124010. https://doi.org/10.1088/1748-9326/9/12/124010

Rocheta E, Evans JP, Sharma A (2020) Correcting lateral boundary biases in regional climate modeling-the effect of the relaxation zone. Clim Dyn 55(9):2511-2521. https://doi.org/10.1007/s00382-020-05393-1 
725 Rodwell MJ, Hoskins B (1996) Monsoons and the dynamics of deserts. Q J R Meteorol Soc 122:1385-1404.

726 https://doi.org/10.1002/qj.49712253408

727 Şahin S, Türkeş M, Wang SH, Hannah D, Eastwood W (2015) Large scale moisture flux characteristics of the 728 Mediterranean basin and their relationships with drier and wetter climate conditions. Clim Dyn 45:3381-3401. 729 https://doi.org/10.1007/s00382-015-2545-X

730 Serrano-Notivoli R, Beguería S, Saz MA, Longares LA, de Luis M (2017) SPREAD: a high-resolution daily gridded 731 precipitation dataset for Spain-an extreme events frequency and intensity overview. Earth Syst Sci Data 9(2):721-738. 732 https://doi.org/10.5194/essd-9-721-2017

733 Sevruk B (1985) Correction of precipitation measurements. Proc workshop on the correction of precipitation measurements. 734 WMO/IAHS/ETH, Zürich, pp 13-13

735 Shahi NK, Das S, Ghosh S, Maharana P, Rai S (2021) Projected changes in the mean and intra-seasonal variability of the 736 Indian summer monsoon in the RegCM CORDEX-CORE simulations under higher warming conditions. Clim Dyn 1-18. 737 https://doi.org/10.1007/s00382-021-05771-3

738 Skamarock WC, Klemp JB, Dudhia J, Gill DO, Barker DM, Duda MG, Huang X-Y, Wang W, Powers JG (2008) A 739 description of the advanced research WRF Version 3. NCAR Technical Notes NCAR/TN-475+STR. 740 https://doi.org/10.5065/D68S4MVH

741 Taylor KE (2001) Summarizing multiple aspects of model performance in single diagram. J Geophys Res Atmos 742 106(D7):7183-7192. https://doi.org/10.1029/2000JD900719

743 Torma C, Giorgi F, Coppola E (2015) Added value of regional climate modeling over areas characterized by complex 744 terrain-Precipitation over the Alps. J Geophys Res Atmos 120:3957-3972. https://doi.org/10.1002/2014JD022781

745 Türkeş M, Erlat E (2006) Influences of the North Atlantic Oscillation on precipitation variability and changes in Turkey.

746 Geophys Space Phys 29:117-135. https://doi.org/10.1393/ncc/i2005-10228-8

747 Warner TT, Peterson RA, Treadon RE (1997) A tutorial on lateral boundary conditions as a basic and potentially serious 748 limitation to regional numerical weather prediction. Bull Am Meteor Soc 78(11):2599-2618. https://doi.org/10.1175/1520749 0477(1997)078\%3C2599:ATOLBC\%3E2.0.CO;2

750 Weisman ML, Skamarock WC, Klemp JB (1997) The resolution dependence of explicitly modeled convective systems. 751 Mon Weather Rev 125(4):527-548. https://doi.org/10.1175/1520-0493(1997)125\%3C0527:TRDOEM\%3E2.0.CO;2

752 Willmott CJ (1982) Some comments on the evaluation of model performance. Bull Am Meteorol Soc 63:1309-1313 
753 Wu W, Lynch AH, Rivers A (2005) Estimating the uncertainty in a regional climate model related to initial and lateral

754 boundary conditions. J Clim 18(7):917-933. https://doi.org/10.1175/JCLI-3293.1

755 Zhou X, Yang K, Ouyang L, Wang Y, Jiang Y, Li X, Chen D, Prein A (2021) Added value of kilometer-scale modeling over

756 the third pole region: a CORDEX-CPTP pilot study. Clim Dyn 1-15. https://doi.org/10.1007/s00382-021-05653-8

757 Zittis G, Bruggeman A, Camera C, Hadjinicolaou P, Lelieveld J (2017) The added value of convection permitting

758 simulations of extreme precipitation events over the eastern mediterranean. Atmos Res 191:20-33.

759 https://doi.org/10.1016/j.atmosres.2017.03.002 
Figures

Model domain and Terrain height (m)

(a) EUR20 simulation

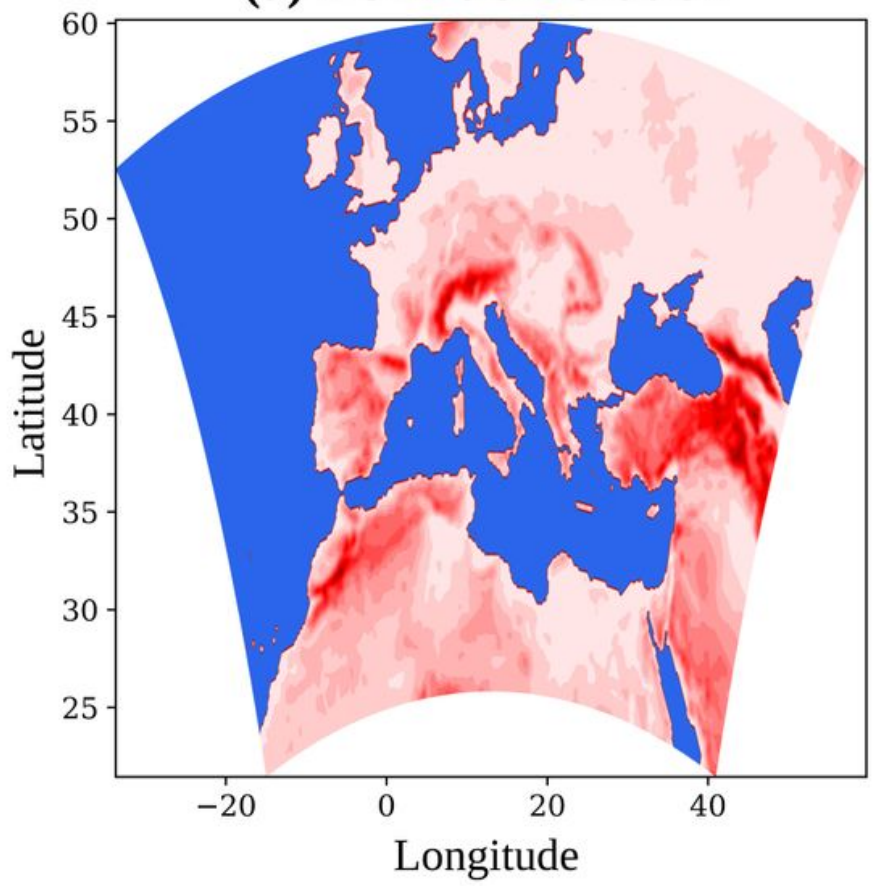

(b) SWE3 simulation

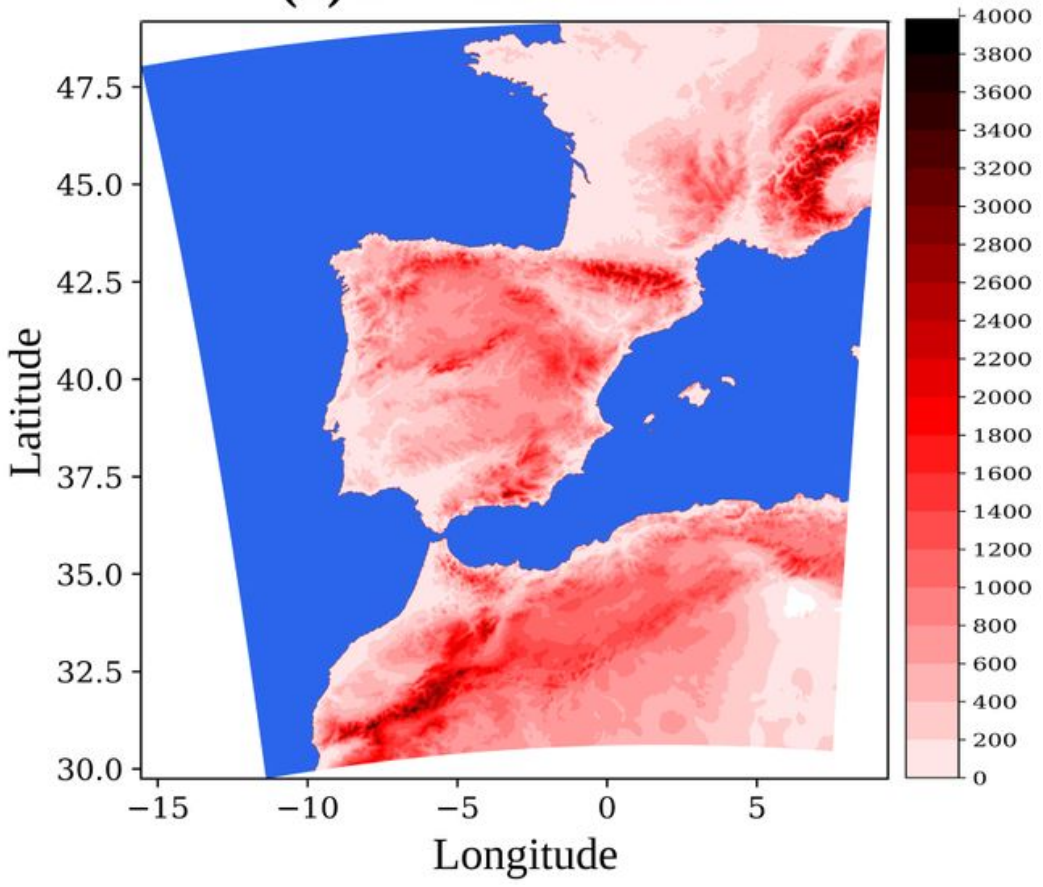

Figure 1

Model domain with terrain height in the meters for the (a) EUR20 simulation and (b) SWE3 simulations. The blue colour represents the ocean. 
Seasonal mean precipitation ( $\mathrm{mm} /$ day) \& relative bias (\%)

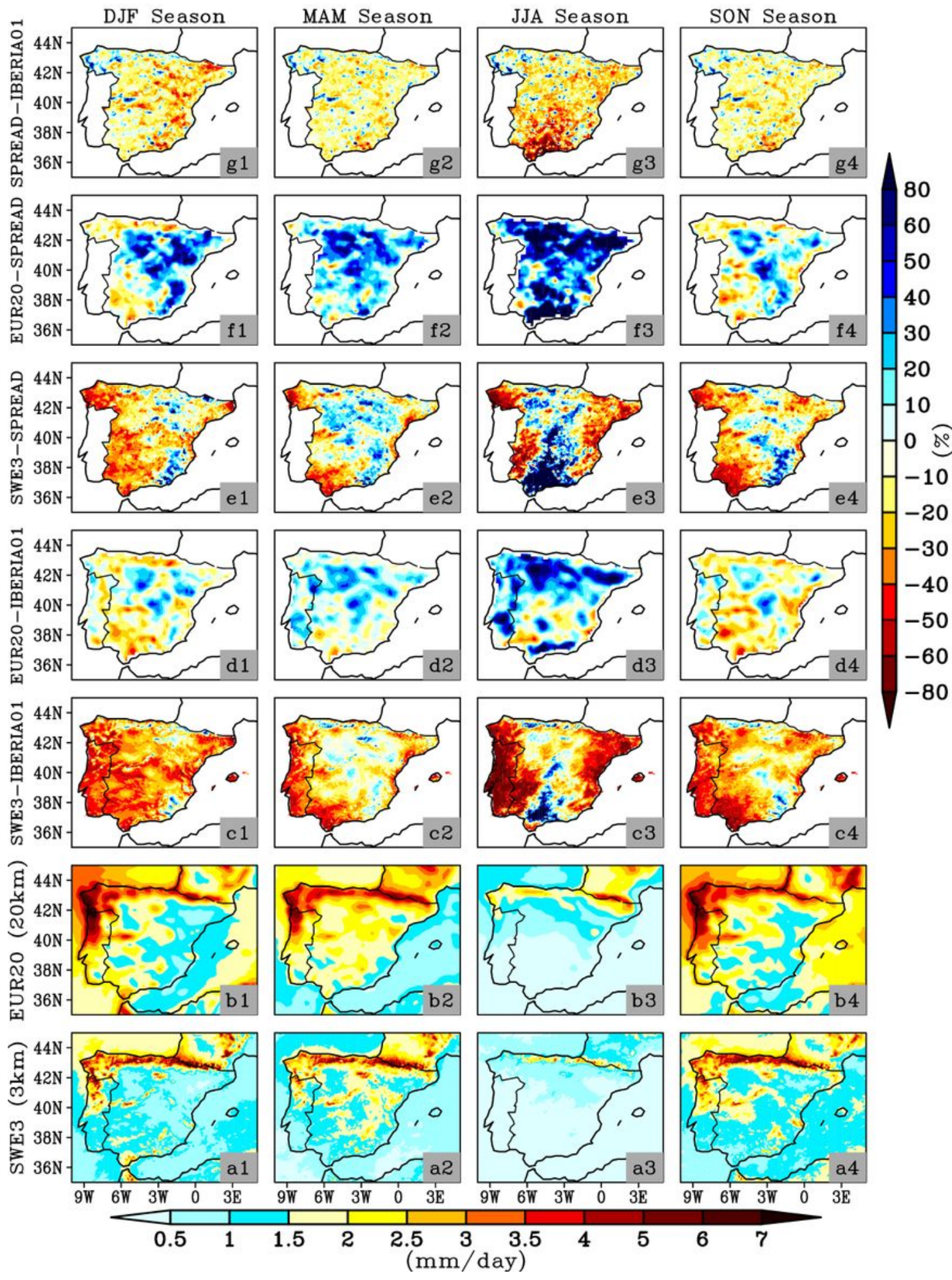

Figure 2

The 10-year (2000-2009) climatological seasonal (DJF, MAM, JJA, and SON) mean precipitation from the (a1-a4) SWE3 and (b1-b4) EUR20 simulations, and relative seasonal mean precipitation bias for each season in the SWE3 \& EUR20 with respect to (c1-c4) \& (d1-d4) IBERIA01, and (e1-e4) \& (f1-f4) SPREAD, respectively. (f1-f4) The relative difference in seasonal mean precipitation between SPREAD and 
IBERIA01 on a $3 \mathrm{~km}$ grid for each season. Units of mean precipitation and bias are in $\mathrm{mm}$ day-1 and percentage (\%), respectively.

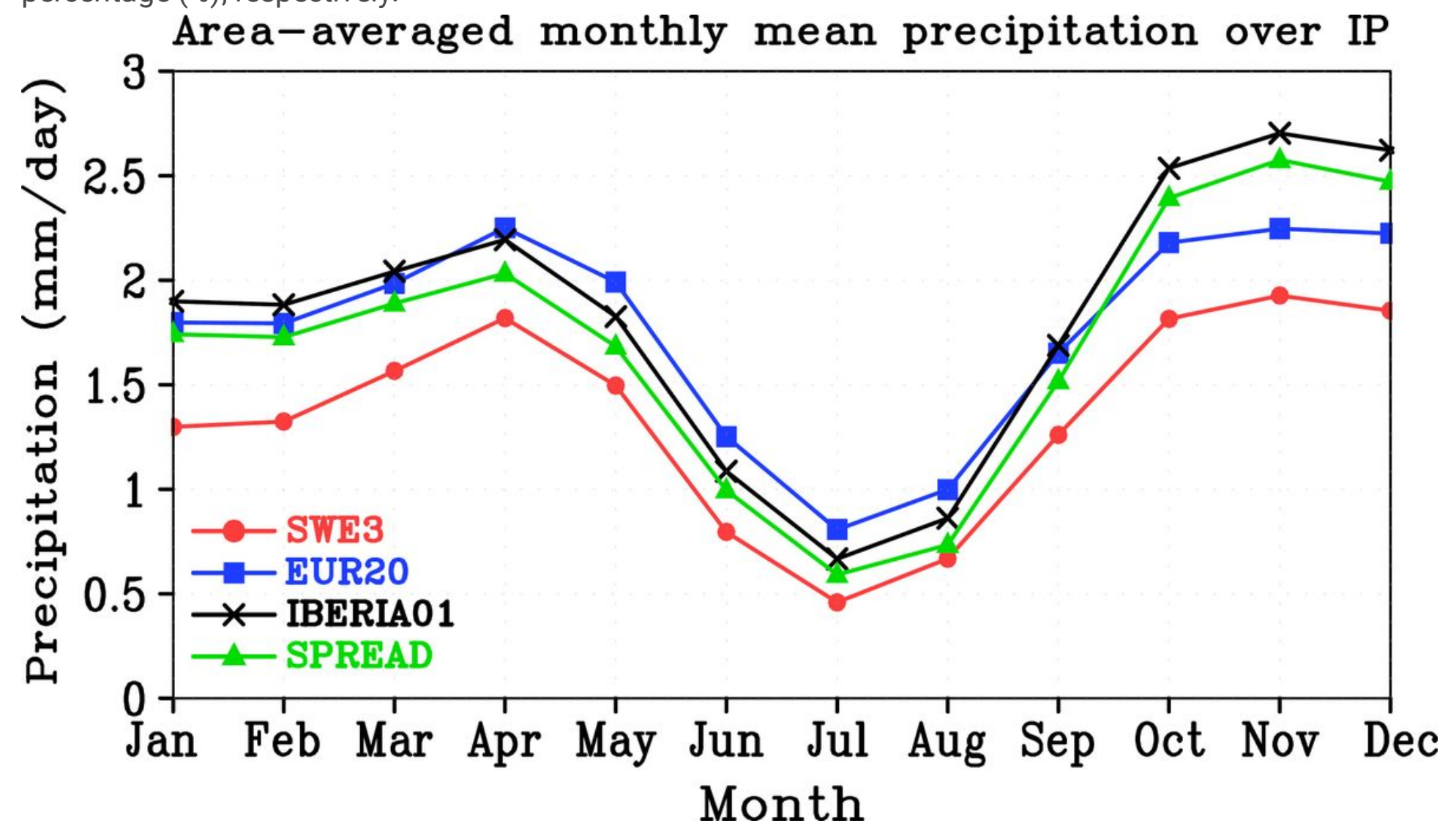

Figure 3

Annual cycle of area-averaged monthly mean precipitation over the Iberian Peninsula (IP, over the area of SPREAD observation) from the SWE3 (red), EUR20 (blue), IBERIA01 (black), and SPREAD (green) during 2000-2009. Units are in $\mathrm{mm}$ day-1. 


\section{Altitudinal variation of mean precipitation}

$(3 \mathrm{~km}$ grid)
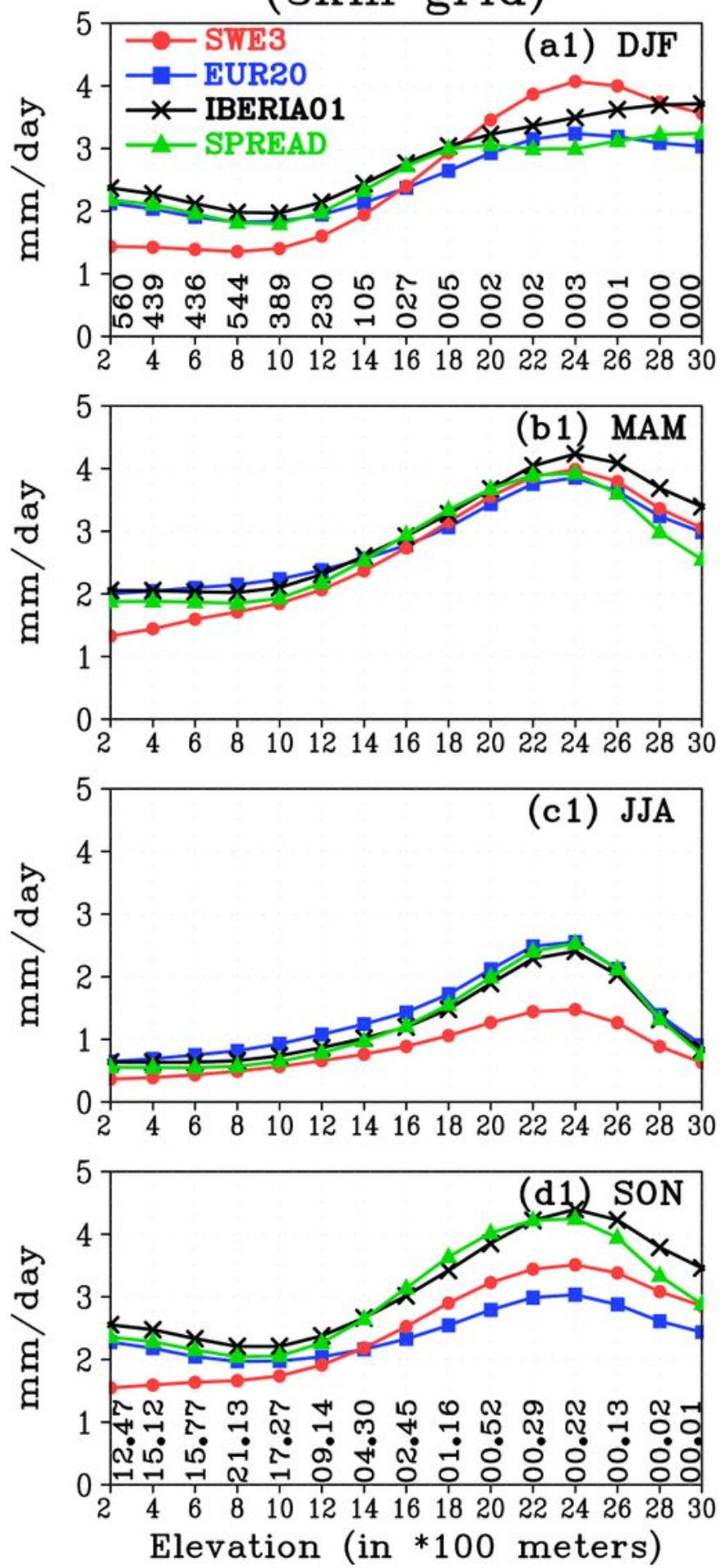

(20km grid)
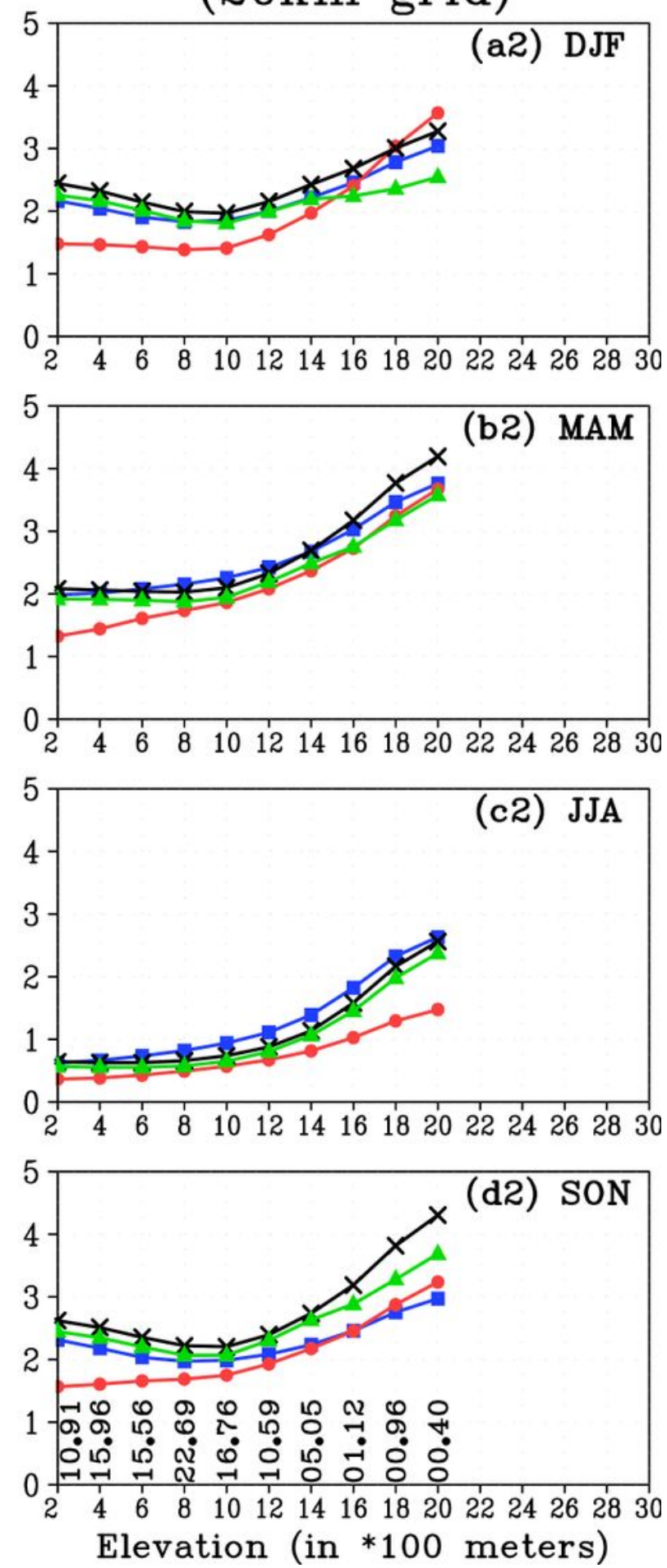

Figure 4

Altitudinal distribution of the mean precipitation from the SWE3 (red), EUR20 (blue), IBERIA01 (black), and SPREAD (green) over the Iberian Peninsula (IP, over the area of SPREAD observation) at $3 \mathrm{~km} \& 20 \mathrm{~km}$ grids for the (a1 \& a2) DJF, (b1 \& b2) MAM, (c1 \& c2) JJA, and (d1 \& d2) SON seasons during 2000-2009. The percentage of the total grid points covered by each class on a (d1) $3 \mathrm{~km}$ and (d2) $20 \mathrm{~km}$ resolutions is 


\section{Vertically Integrated Moisture Transport (VIMT)}
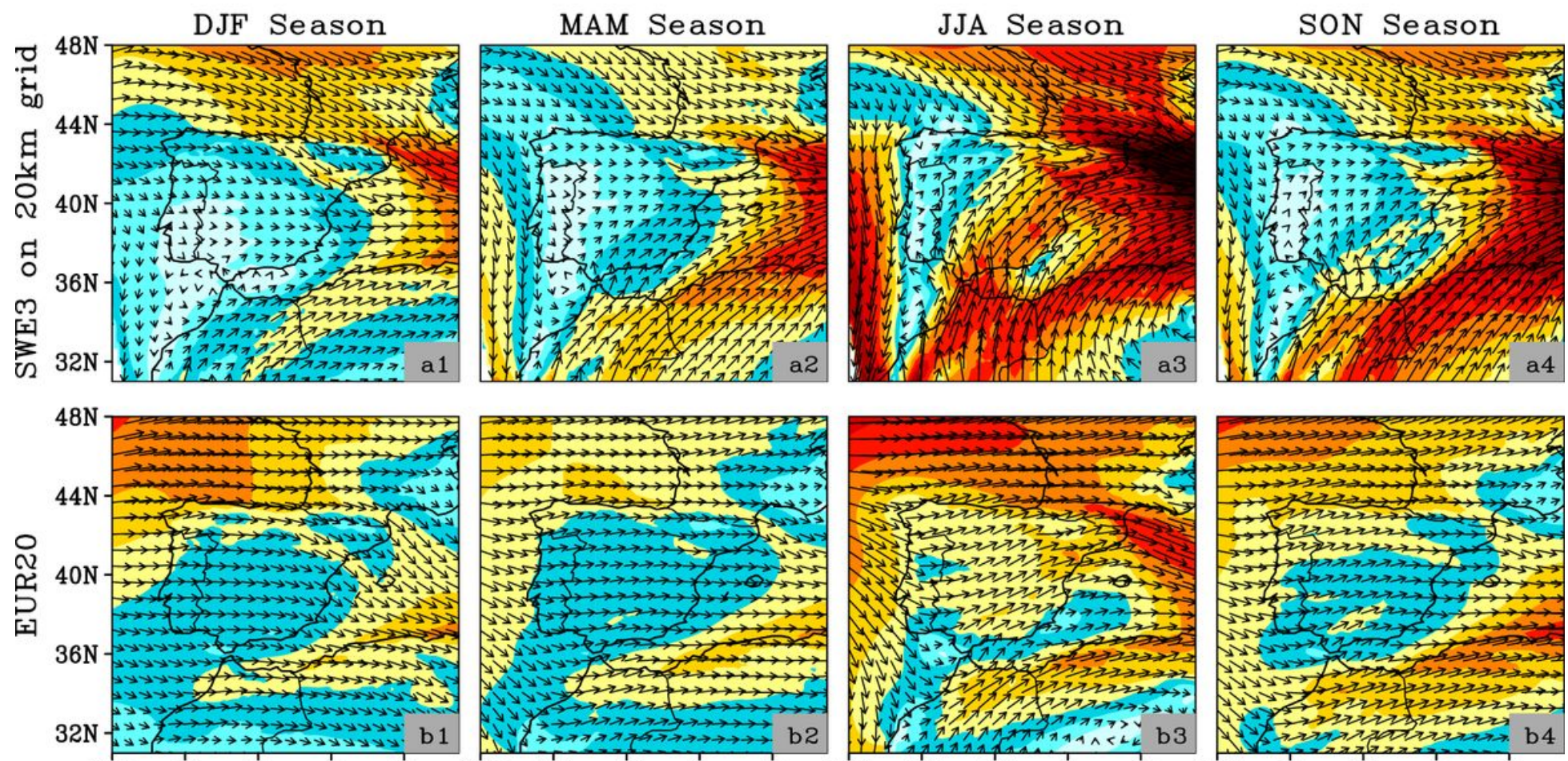

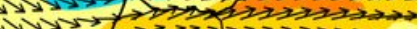

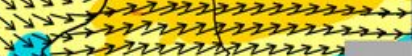

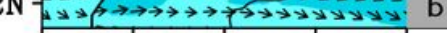
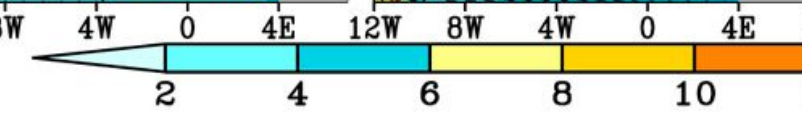

unit: $\mathrm{x} 10 \sim 4[\mathrm{~m} / \mathrm{s}][\mathrm{g} / \mathrm{kg}]$

\section{Figure 5}

Vertically integrated moisture transport from the SWE3 (EUR20) for the a1 (b1) DJF, a2 (b2) MAM, a3 (b3) JJA, and a4 (b4) SON seasons during 2000-2009. The shaded color represents the magnitude of the wind and the vectors represent the wind direction. Units are in $x 104[\mathrm{~m} / \mathrm{s}][\mathrm{g} / \mathrm{kg}]$. 
Vertically Integrated Moisture Flux Convergence (VIMFC)
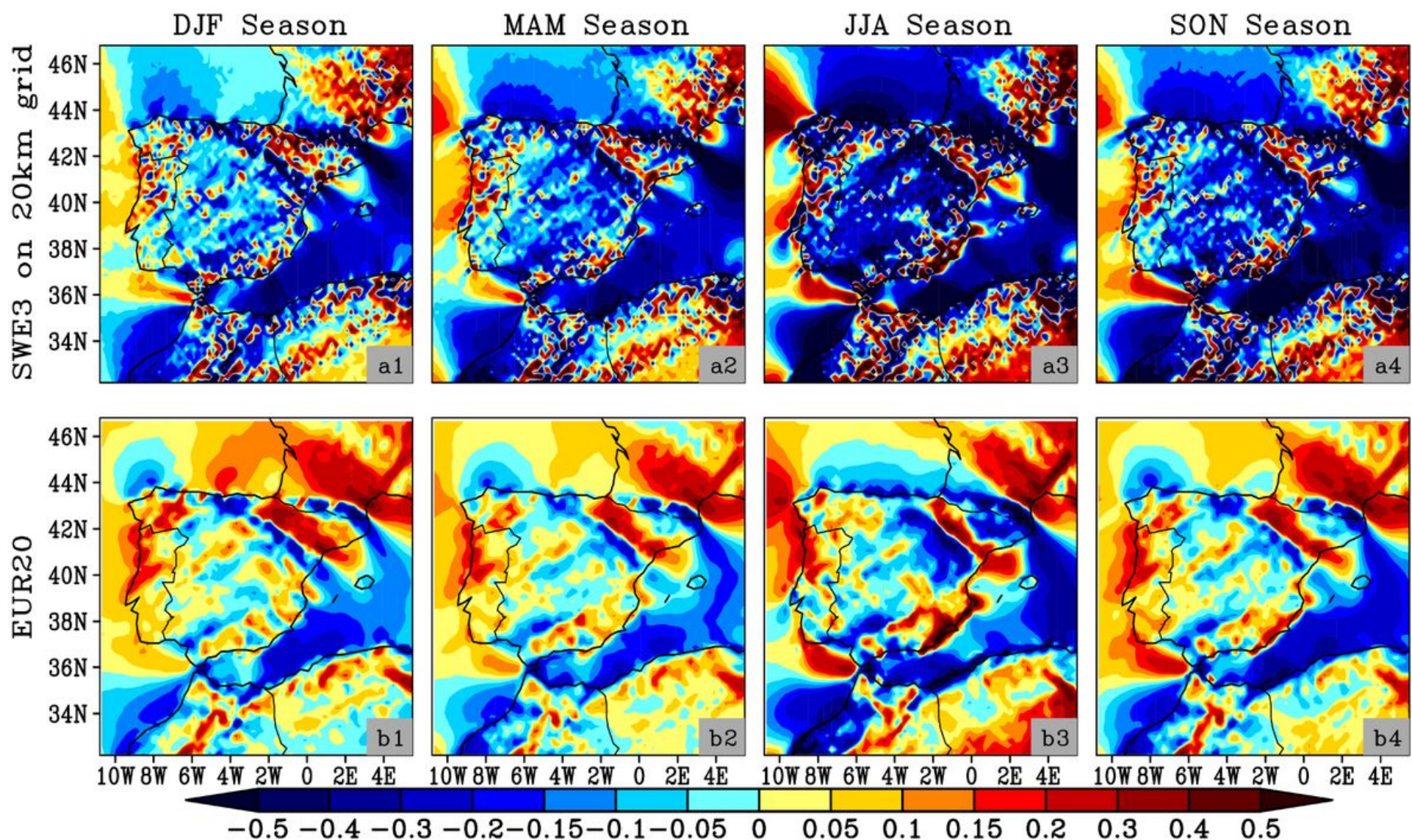

10W $8 \mathrm{~W} \quad 6 \mathrm{~W} \quad 4 \mathrm{~W} \quad 2 \mathrm{~W} \quad 0 \quad 2 \mathrm{E} \quad 4 \mathrm{E}$

$10 \mathrm{~W} 8 \mathrm{~W} \quad 6 \mathrm{~W} \quad 4 \mathrm{~W} \quad 2 \mathrm{~W} \quad \mathrm{O}_{2} \quad 2 \mathrm{E} \quad 4 \mathrm{E}$

$10 \mathrm{~W} 8 \mathrm{~W} \quad 6 \mathrm{~W} \quad 4 \mathrm{~W} \quad 2 \mathrm{~W} \quad 0 \quad 2 \mathrm{E} \quad 4 \mathrm{E}$

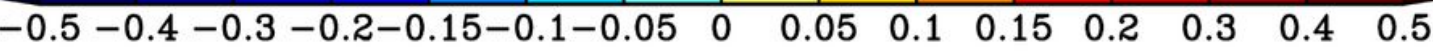

unit: $g \mathrm{~m} \wedge-2 \mathrm{~s} \wedge-1$

Figure 6

Vertically integrated moisture flux convergence from the SWE3 (EUR20) for the a1 (b1) DJF, a2 (b2) MAM, a3 (b3) JJA, and a4 (b4) SON seasons during 2000-2009. Units are in g m-2 s-1. 
Frequency and Intensity (days where precipitation $>=1 \mathrm{~mm}$ )
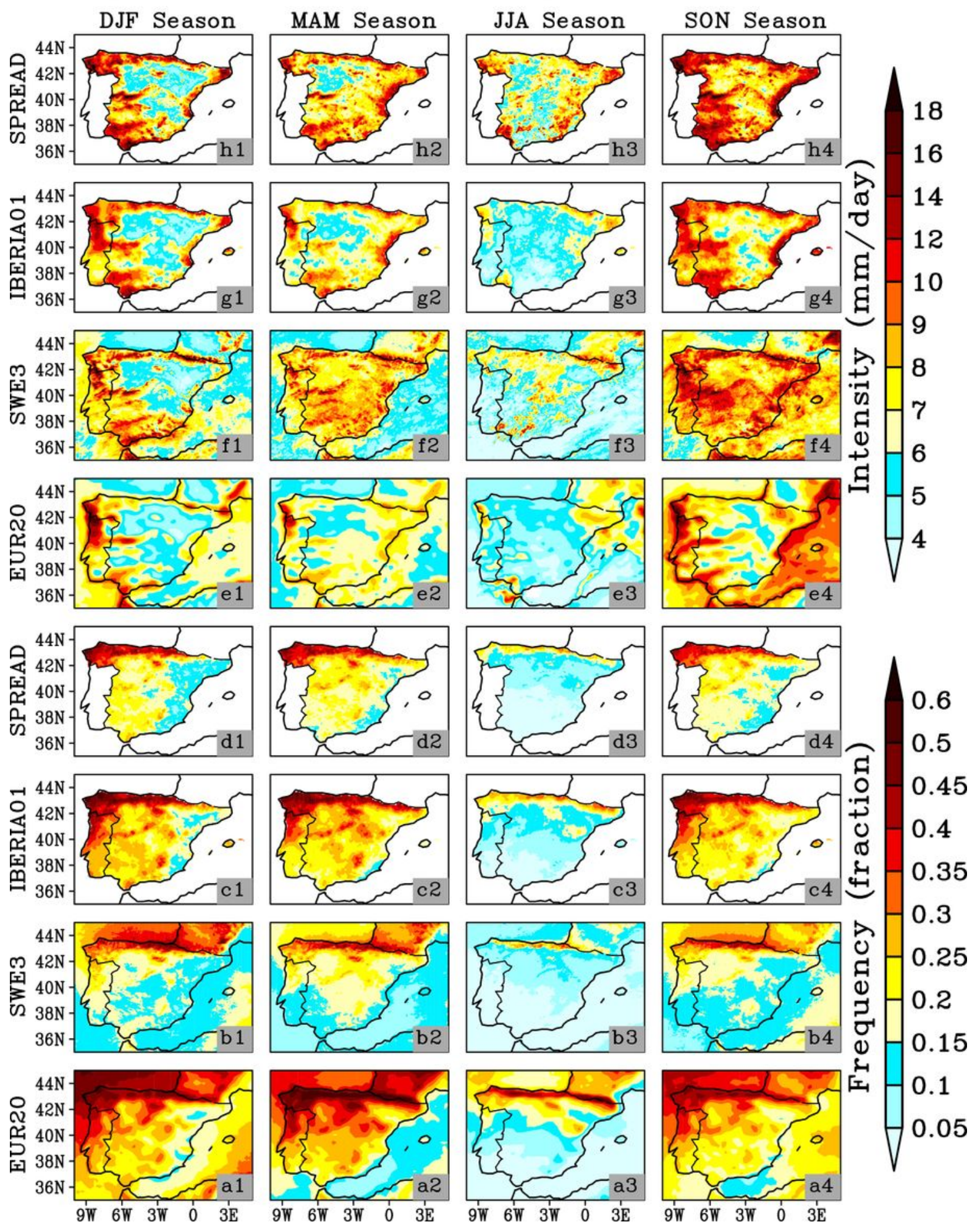

Figure 7

Frequency \& intensity of the precipitation (days where precipitation $>=1 \mathrm{~mm}$ ) for each seasons (DJF, MAM, JJA, and SON) from the (a1-a4) \& (e1-e4) EUR20, (b1-b4) \& (f1-f4) SWE3, (c1-c4) \& (g1-g4) IBERIA01, and (d1-d4) \& (h1-h4) SPREAD; respectively during 2000-2009. Units of frequency and intensity are in fraction and $\mathrm{mm}$ day-1, respectively. 
Altitudinal variation of precipitation frequency $(\mathrm{pr}>=1 \mathrm{~mm}$ )

(3km grid)
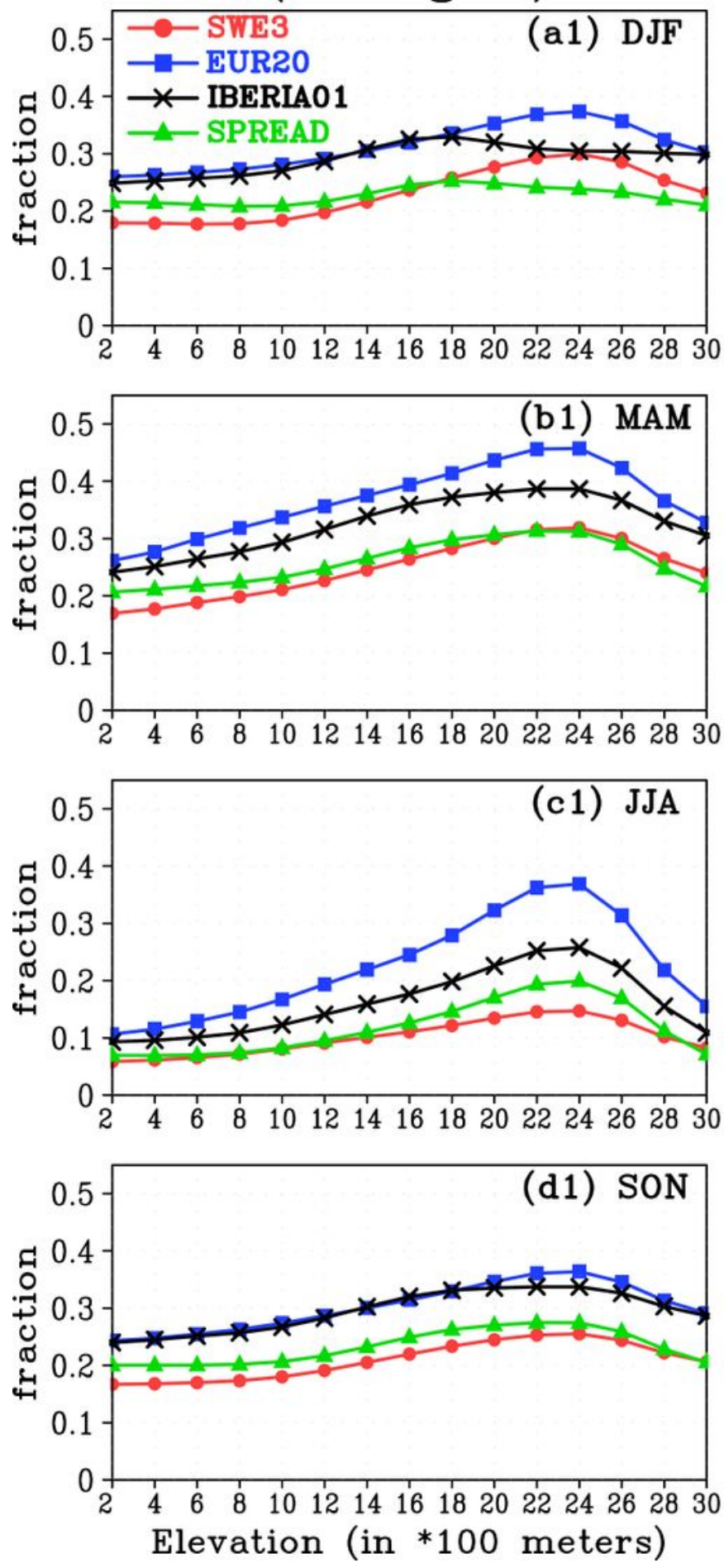

$(20 \mathrm{~km}$ grid)
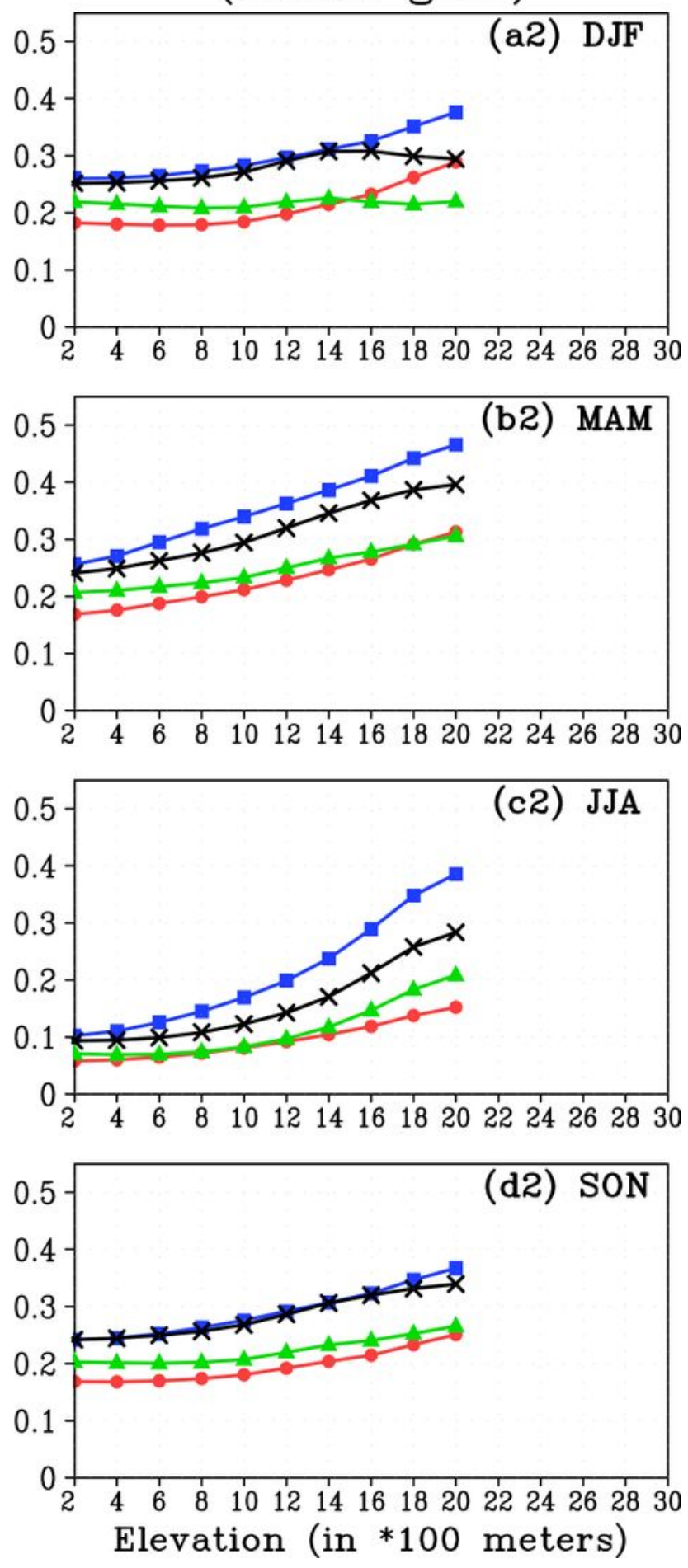

\section{Figure 8}

Altitudinal distribution of precipitation frequency (days where precipitation $>=1 \mathrm{~mm}$ ) from the SWE3 (red), EUR20 (blue), IBERIA01 (black), and SPREAD (green) over the Iberian Peninsula (IP, over the area of SPREAD observation) at 3km \& $20 \mathrm{~km}$ grids for the (a1 \& a2) DJF, (b1 \& b2) MAM, (c1 \& c2) JJA, and (d1 $\&$ d2) SON seasons during 2000-2009. x-axis panels represent the elevation class of $200 \mathrm{~m}$. Units are in fraction. 
Altitudinal variation of precipitation intensity $(\mathrm{pr}>=1 \mathrm{~mm})$

(3km grid)
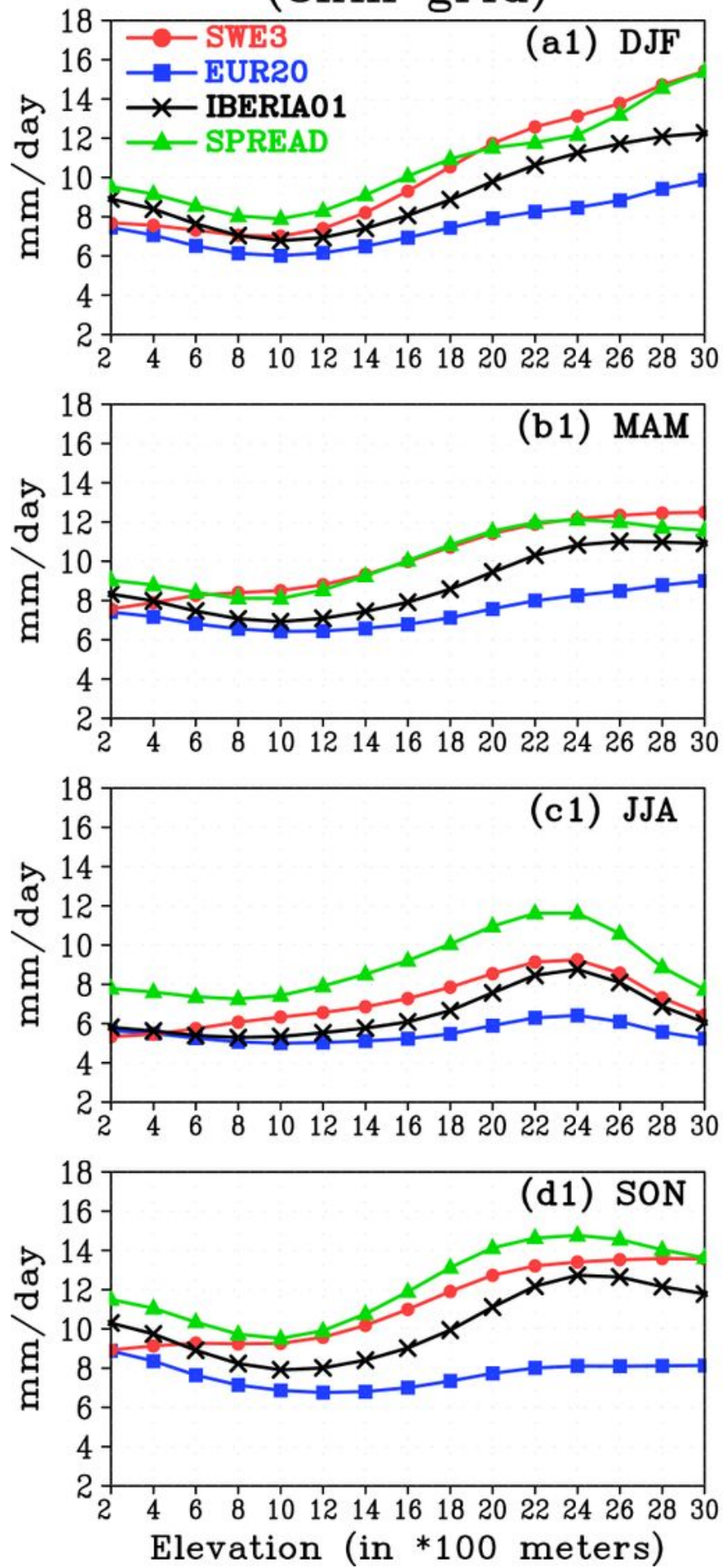

(20km grid)
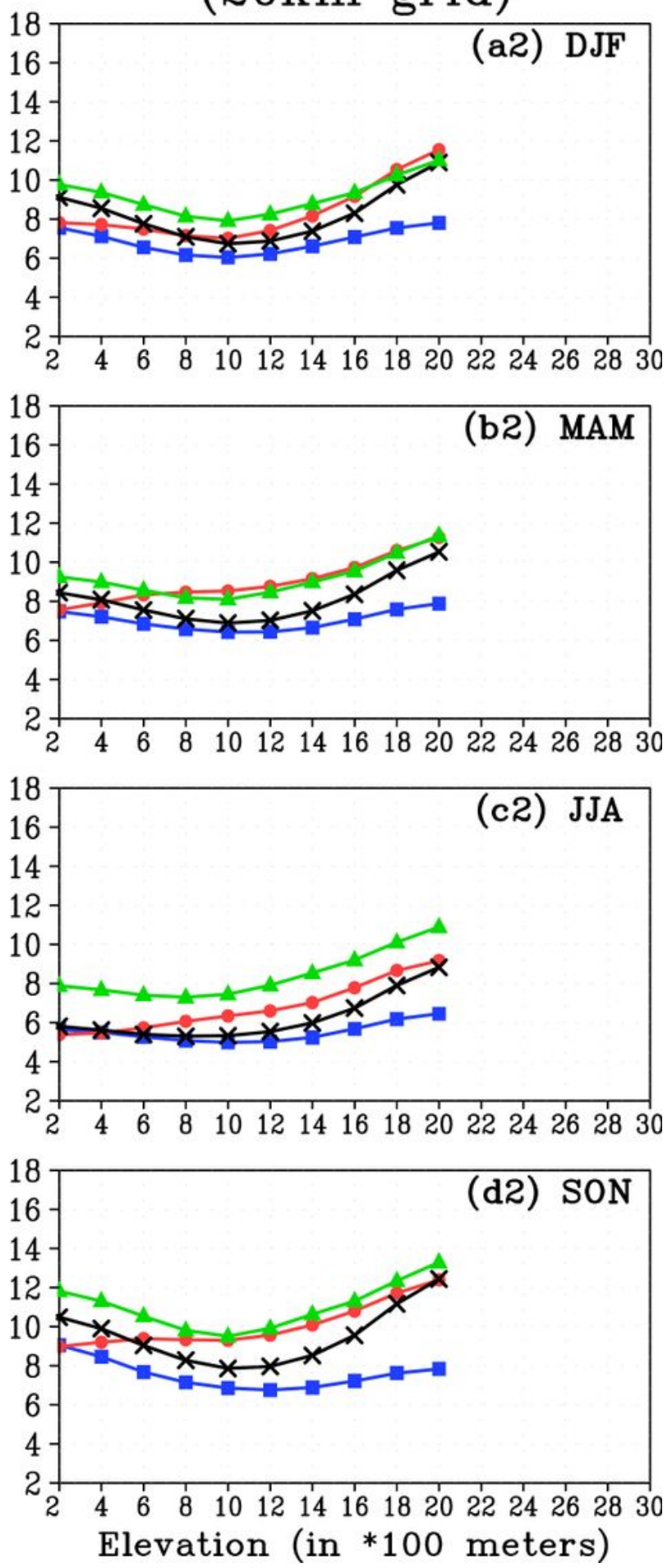

Figure 9

Altitudinal distribution of precipitation intensity (days where precipitation $>=1 \mathrm{~mm}$ ) from the SWE3 (red), EUR20 (blue), IBERIA01 (black), and SPREAD (green) over the Iberian Peninsula (IP, over the area of SPREAD observation) at 3km \& 20km grids for the (a1 \& a2) DJF, (b1 \& b2) MAM, (c1 \& c2) JJA, and (d1 $\&$ d2) SON seasons during 2000-2009. $x$-axis panels represent the elevation class of $200 \mathrm{~m}$. Units are in $\mathrm{mm}$ day-1. 


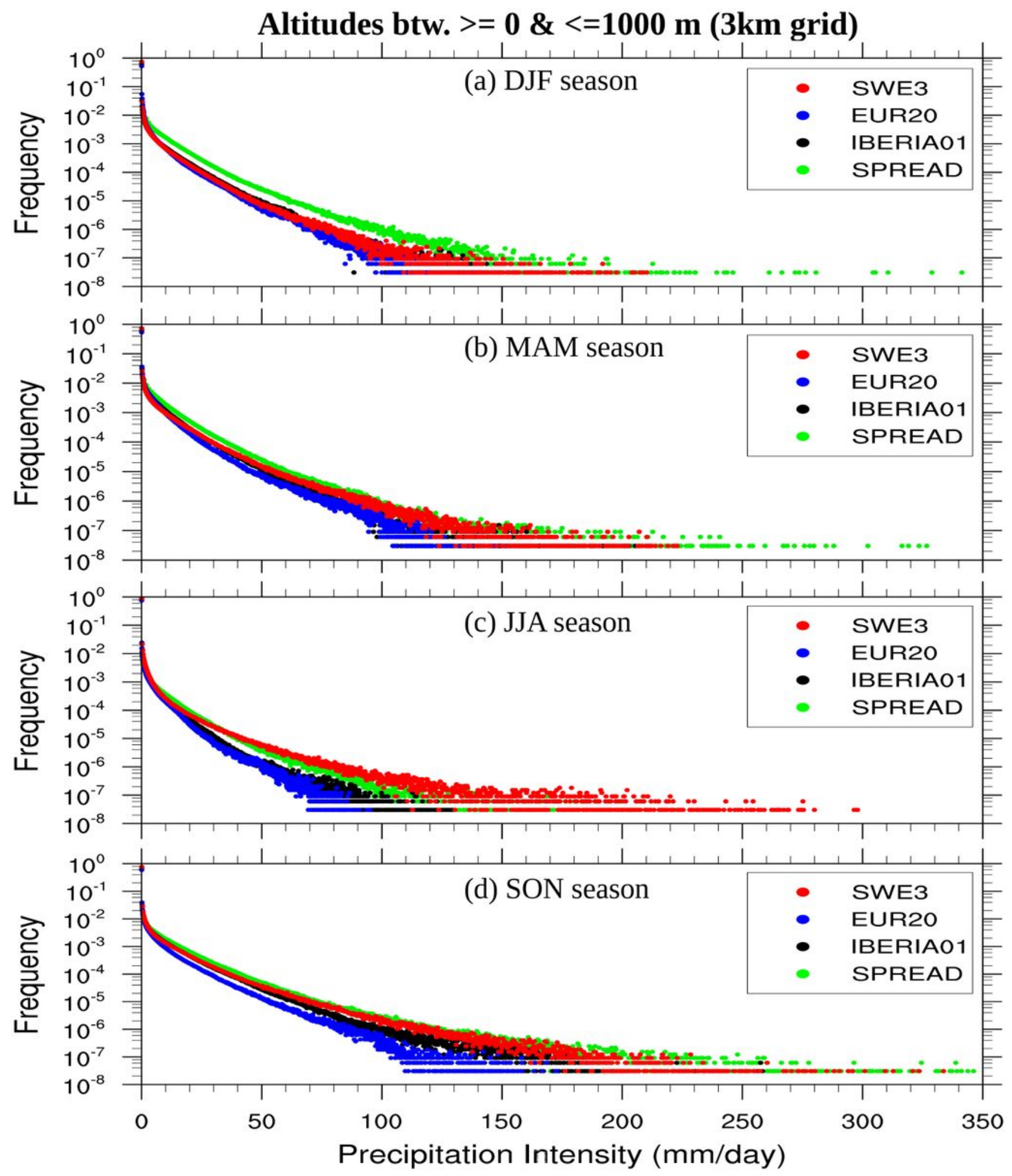

Figure 10

Probability density functions (PDFs) of daily mean precipitation (frequency versus intensity) over the Iberian Peninsula (IP, over the area between the altitudes of $>=0$ and $<=1000 \mathrm{~m}$ of the SPREAD observation) from the SWE3 (red), EUR20 (blue), IBERIA01 (black), and SPREAD (green) interpolated onto the $3 \mathrm{~km}$ resolution grid for (a) DJF, (b) MAM, (c) JJA, and (d) SON seasons during 2000-2009. Units are in $\mathrm{mm}$ day-1. 


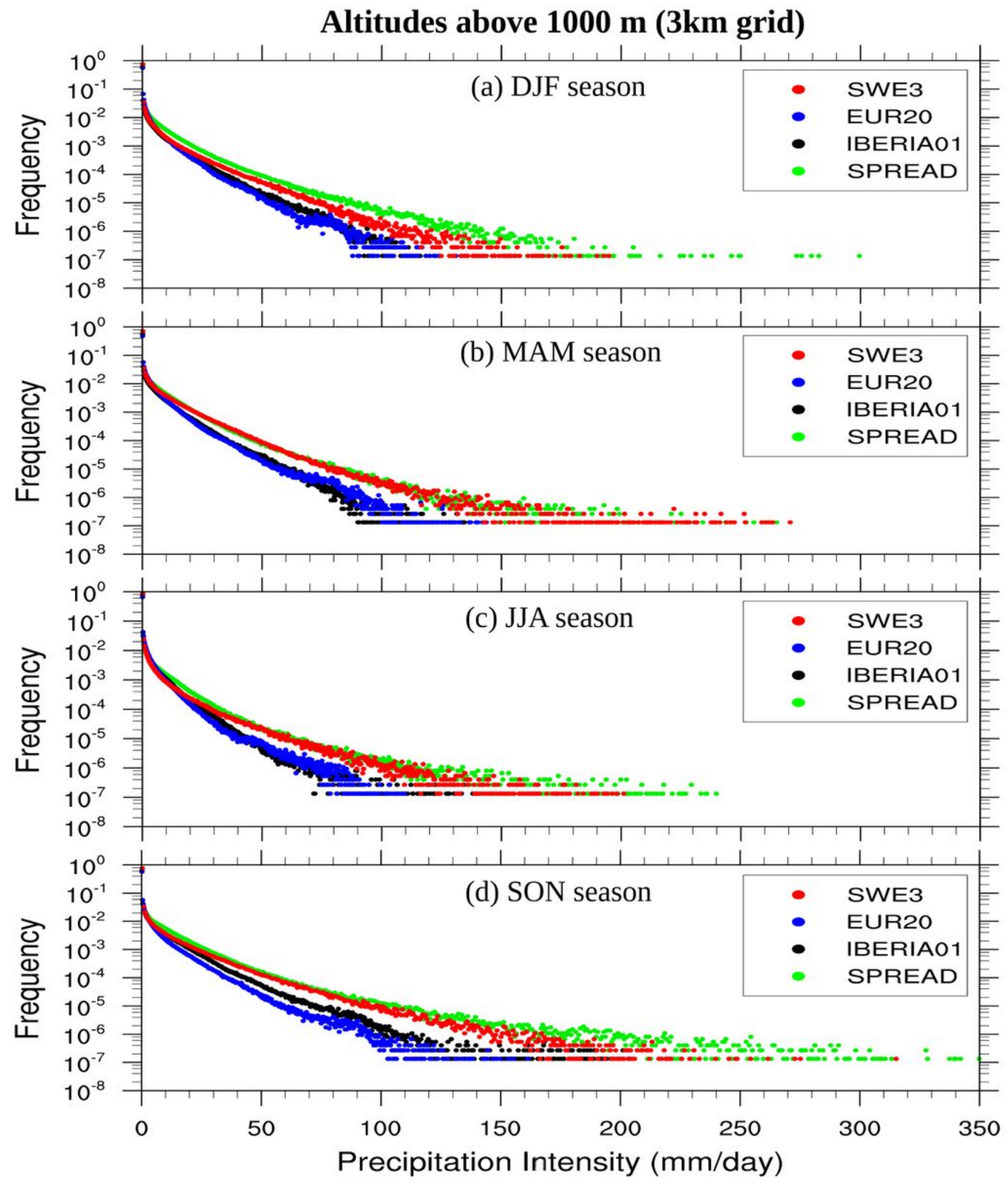

Figure 11

Probability density functions (PDFs) of daily mean precipitation (frequency versus intensity) over the Iberian Peninsula (IP, over the area above the altitudes of $1000 \mathrm{~m}$ of the SPREAD observation) from the SWE3 (red), EUR20 (blue), IBERIA01 (black), and SPREAD (green) interpolated onto the $3 \mathrm{~km}$ resolution grid for (a) DJF, (b) MAM, (c) JJA, and (d) SON seasons during 2000-2009. Units are in mm day-1. 


\section{Kolmogorov-Smirnov (KS) distance [3km grid]}
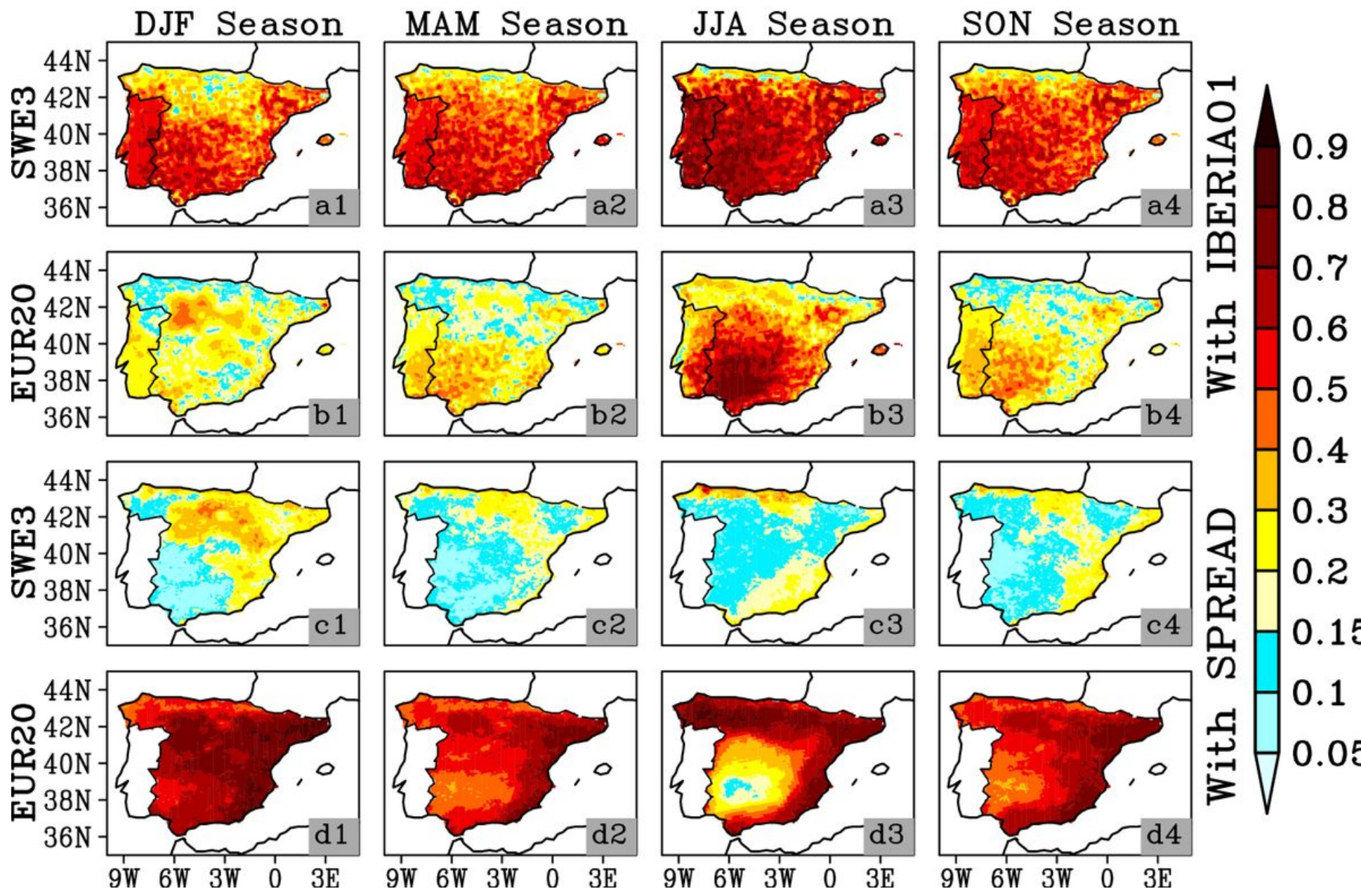

0.4

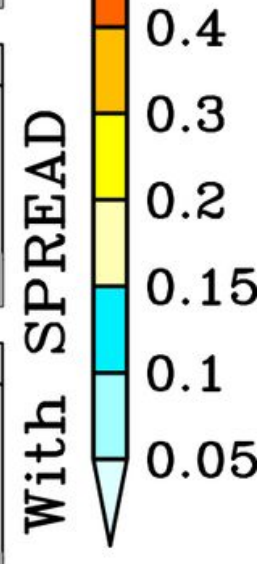

Figure 12

The Kolmogorov-Smirnov distance between simulated (SWE3 \& EUR20) and observed (SPREAD \& IBERIA01) CDFs of daily precipitation for each season during 2000-2009 on a $3 \mathrm{~km}$ grid resolution. Results from the (a1-a4) SWE3 \& (b1-b4) EUR20 with IBERIA01, and (c1-c4) SWE3 (d1-d4) EUR20 with SPREAD. 

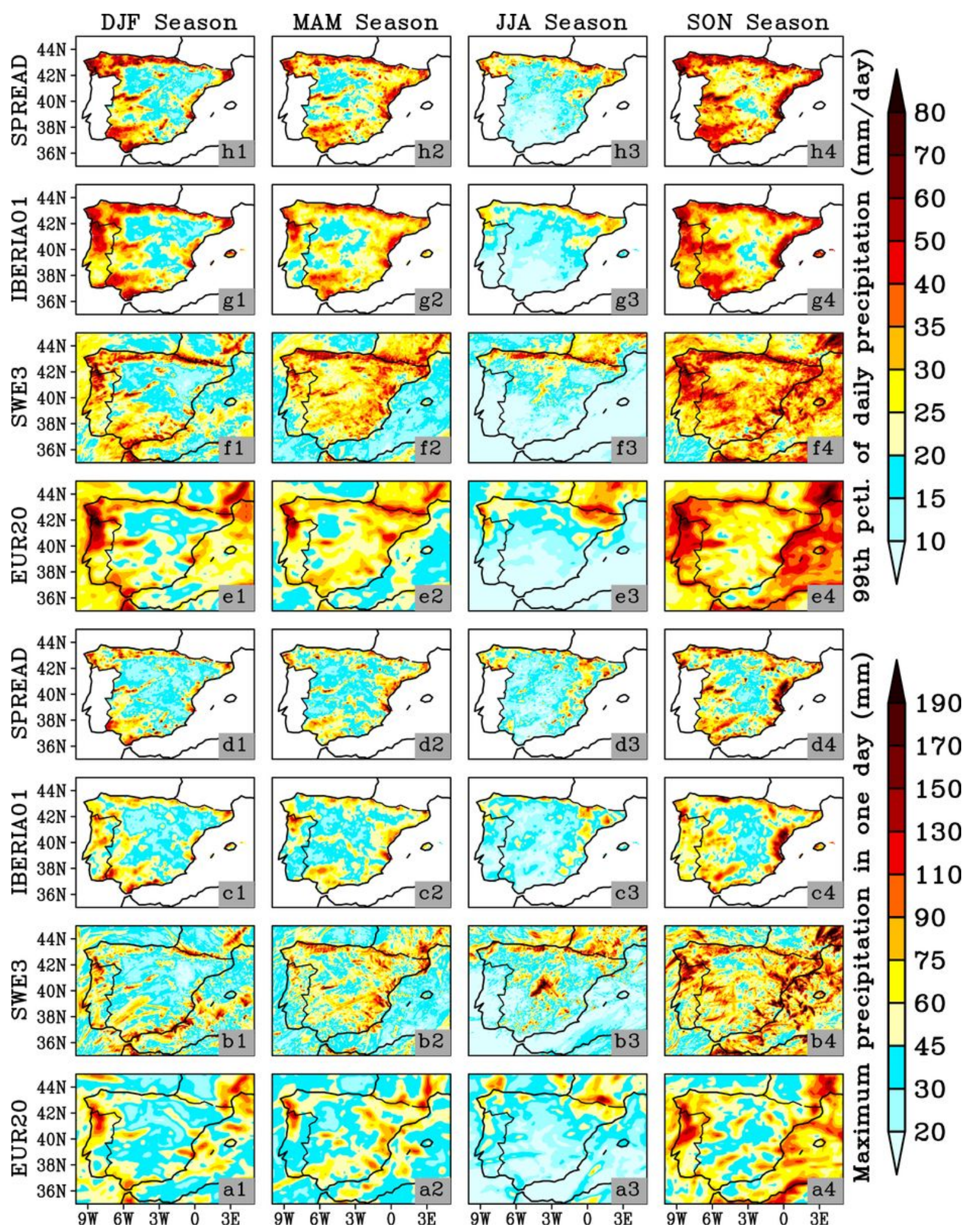

\section{Figure 13}

Maximum one day precipitation amount (Rx1day) \& 99th percentile (R95p) of daily mean precipitation for each seasons (DJF, MAM, JJA, and SON) from the (a1-a4) \& (e1-e4) EUR20, (b1-b4) \& (f1-f4) SWE3, (c1c4) \& (g1-g4) IBERIA01, and (d1-d4) \& (h1-h4) SPREAD; respectively during 2000-2009. Units of Rx1day and $\mathrm{R} 95 \mathrm{p}$ are in $\mathrm{mm}$ and $\mathrm{mm}$ day- 1 , respectively. 


\section{Supplementary Files}

This is a list of supplementary files associated with this preprint. Click to download.

- Supplementaryfigures.pdf 